\title{
What's in an Occupation? Investigating Within-Occupation Variation and Gender Segregation Using Job Titles and Task Descriptions
}

\author{
Ananda Martin-Caughey \\ New York University
}

Corresponding Author: Ananda Martin-Caughey, New York University, 295 Lafayette Street, 4th Floor, New York, NY 10012

Email: amc1320@nyu.edu

\begin{abstract}
Occupations have long been central to the study of inequality and mobility. However, the occupational categories typical in most U.S. survey data conceal potentially important patterns within occupations. This project uses a novel data source that has not previously been released for analysis: the verbatim text responses provided by respondents to the General Social Survey from 1972 to 2018 when asked about their occupation. These text data allow for an investigation of variation within occupations, in terms of job titles and task descriptions, and the occupation-level factors associated with this variation. I construct an index of occupational similarity based on the average pairwise cosine similarity between job titles and between task descriptions within occupations. Findings indicate substantial variation in the level of similarity across occupations. Occupational prestige, education, and income are associated with less heterogeneity in terms of job titles but slightly more heterogeneity in terms of task descriptions. Gender diversity is associated with more internal heterogeneity in terms of both job titles and task descriptions. In addition, I use the case of gender segregation to demonstrate how occupational categories can conceal the depth and form of stratification.
\end{abstract}

\section{Keywords}

stratification, within-occupation variation, occupations and jobs, occupational closure, gender segregation

\section{$\langle$ text $>$}

Occupations have long been central to the study of inequality and mobility in the United States (Blau and Duncan 1967; Featherman and Hauser 1978; Weeden and Grusky 2005). As technology alters the tasks and skills required in the labor market, occupations have received renewed attention from scholars interested in inequality and the future of work (Anteby, Chan, and DiBenigno 2016; Autor 2019; Frey and Osborne 2017; Mouw and Kalleberg 2010; Xie, Killewald, and Near 2016).

However, the occupational categories typical in most survey data conceal potentially important variation within occupations. Traditional survey data usually only include an occupational code for each respondent, and researchers do not have access to respondents' actual job titles or descriptions of their work (Avent-Holt et al. 2019). Of course, this categorization is often necessary to protect personally identifiable information and to simplify analyses, but it means quantitative studies that involve occupations are limited to predefined categories that may conceal important patterns.

Additionally, the occupational schemes that most social science research relies on are developed through a complex process by the U.S. Census Bureau that changes every decade (Scopp 2003). The Census Bureau strives to aggregate jobs that are similar in terms of tasks and skills, but researchers do not have comprehensive information about how similar the jobs really are, or how the similarity may vary across occupations and over time. Some occupations are probably very internally cohesive and are good representations of the work incumbents do. Other occupations are probably catch-all categories or involve a lot of specialization or 
hierarchy, leading to substantial internal variation in terms of jobs and tasks. Understanding this variation is important both for evaluating occupations as useful concepts and for interpreting findings from the many stratification studies that use these categories.

Furthermore, these data limitations mean we know little about how people are sorted into different jobs within occupations. An occupation is "an abstract category used to group and classify similar jobs," whereas a job is "a specific and sometimes unique bundle of activities carried out by a person in the expectation of economic remuneration" (Hauser and Warren 1997:180). Jobs (and workplaces) may be as important or even more important than occupations in the stratification process (Avent-Holt et al. 2019).

One example of how occupations may conceal the extent and form of inequality is the case of gender segregation. Occupational segregation by gender is an enduring feature of the U.S. labor market and the primary cause of the gender wage gap (Charles and Grusky 2005; England, Levine, and Mishel 2020; Tomaskovic-Devey 1993a). Although the labor market has become more integrated over the past several decades, men and women still tend to concentrate in different kinds of work. However, our measures of segregation depend on the categories of occupations observed and their level of aggregation (Bielby and Baron 1984, 1986; Tomaskovic-Devey 1993b). Occupations that appear relatively integrated by gender may actually consist of jobs that are highly segregated. People who study occupational segregation know this, and sometimes adjust their estimates accordingly (Tomaskovic-Devey et al. 2006), but little research actually measures segregation at more detailed levels, especially at the national level.

To shed light on these issues, this study uses a novel data source: the job names and task descriptions provided by respondents to the General Social Survey (GSS) from 1972 to 2018. These data, which have not previously been released for analysis, allow me to analyze the detail behind the occupational codes present in traditional surveys. They offer a rare opportunity to analyze nationally representative data on job names and tasks within occupations in the United States. Specifically, I ask the following three questions: (1) How much variation in terms of job names and task descriptions is present within occupational categories? (2) At the occupational level, what factors are associated with the level of variation? (3) To what extent do occupations conceal gender segregation at the job-title level?

After preprocessing the text data, I assign similarity scores to each occupation from the Census's 2010 occupational scheme based on the average pairwise cosine similarity between job names and between task descriptions. Cosine similarity is a commonly used measure in text analysis that indicates the level of similarity between two texts based on unordered word usage (Manning, Raghavan, and Schütze 2008). I find substantial variation within occupations, and different rates of variation across occupations, both in terms of job names and task descriptions. I also find evidence that job names and task descriptions are becoming more heterogeneous over time.

I then predict similarity based on a vector of occupation-level covariates. Findings indicate that higher-status occupations (in terms of prestige, average income, and average education) tend to be substantially more internally similar in terms of job names but slightly less similar in terms of task descriptions. Furthermore, gender diversity is strongly associated with occupational heterogeneity, suggesting jobs may be a mechanism for differentiating men and women within integrating occupations.

In the final section of the article, I examine how men and women are sorted into different job titles within occupations, by calculating indices of segregation at different levels of aggregation for the past five decades. Consistent with prior research, I demonstrate how measuring 
segregation based on job titles, rather than occupations, increases overall estimates of gender segregation in the United States. However, I also show how the level of job-title segregation is unevenly distributed across the labor market, and I present preliminary evidence that the rate of job desegregation may be slowing relative to occupational desegregation.

Aggregation is a necessary if not a defining feature of social science. However, it is critical to understand what goes into the aggregation process and to investigate what is concealed, particularly in the study of inequality and stratification. This is true not just for occupations, but for all major categories in social science, from educational categories, to racial groups, to neighborhoods. This article helps open the black box of occupational categories and uses the case of gender segregation to demonstrate the deeper forms and patterns of inequality masked by categorization.

\section{OCCUPATIONAL CATEGORIES}

Sociological research on stratification and mobility has relied heavily on the concept of occupations for decades, from status attainment models to class analysis (Blau and Duncan 1967; Erikson and Goldthorpe 1992; Weeden and Grusky 2005, 2012). Occupations are generally defined as categories of work containing similar tasks within the division of labor. Occupations are also conceptualized as status groupings, generating a hierarchy of prestige across the occupational structure (Avent-Holt et al. 2019).

Dramatic changes in the U.S. labor market over the past few decades, including the growth in earnings inequality and the decline of firm internal labor markets, have led to increased attention on occupations. For example, Autor, Katz, and Kearney (2006) argue that the rise in earnings inequality can be attributed to polarized growth in occupational employment due to technological change. In addition, Mouw and Kalleberg (2010) contend that occupations remain critical in understanding inequality, finding that between-occupation inequality has risen faster than within-occupation inequality. Anteby and colleagues (2016) argue that occupational affiliations are strengthening as organizational affiliations decline due to workers changing employers more often than in the past.

Although occupations feature prominently in research on inequality, mobility, and work, quantitative researchers generally have little control over how the concept is measured in practice. The major surveys used in U.S. social science research, including the Current Population Survey (CPS) and the American Communities Survey (ACS), typically measure occupation in terms of the Census Bureau's occupational classification system. These schemes represent only a "particular construction" of occupations "imposed over time by a governmental body" (Anteby et al. 2016:187). In this way, they imperfectly operationalize sociologists' conceptions of occupations.

The Census's classification system has changed dramatically over the past six decades (Scopp 2003). In 1970, the Census increased the number of occupational categories from 297 to 441 in response to requests from users for more detail. In 1980, federal agencies adopted the Standard Occupational Classification (SOC), revamping the classification system entirely, then built a new SOC from scratch again in 2000 (Scopp 2003:8). In the new SOC, work was organized into "job families" based on where people work, whereas the previous system divided workers mainly on the basis of skill levels. The 2010 Census occupation scheme - used in this studyincludes 540 four-digit occupations (referred to as "detailed occupations" in the remainder of this article). Thus, for much of the quantitative research on occupations in the United States, researchers see a four-digit code but have little information about underlying similarity in terms of jobs and tasks. ${ }^{1}$ 
Occupational classification is further complicated by evidence that occupational coding (i.e., the process by which survey respondents are matched to occupations) may be less reliable than previously thought (Kim, Kim, and Ban 2020; Mathiowetz 1992; Mellow and Sider 1983). Kim and colleagues (2020) find high mismatch rates between independent coders, using data from the Korean Social Survey. Mellow and Sider (1983) and Mathiowetz (1992) find high levels of disagreement between employer and employee reports of occupation.

The peculiarities of the occupational classification systems, and their inconsistencies over time, present a challenge for social scientists. Occupations are central to theories of inequality, mobility, and work life, but the way they are measured in surveys depends on an inconsistent and complex process led by institutions with different goals from sociologists. Underlying data on actual jobs are often unavailable, and data that do exist on job titles and tasks generally do not include distributional information at the national level. ${ }^{2}$ Scholars make the best of the situation by aggregating detailed occupations into larger categories that are more consistent over time, but this approach sacrifices a potentially important level of detail, and the underlying data remain flawed.

Of course, researchers have tools for investigating within-occupation heterogeneity based on a variety of dimensions, such as income, demographics, industry composition, contract type, job satisfaction, and employment status (e.g., Jencks, Perman, and Rainwater 1988; Katz and Krueger 2019; Mouw and Kalleberg 2010; Sakamoto and Wang 2020). To the extent that these forms of heterogeneity are correlated with job and task heterogeneity, these measures can help us assess the cohesiveness of occupational categories. However, scholars generally do not have access to direct measures of job and task heterogeneity. Because jobs and tasks are the basis for occupational classification, and therefore help explain other forms of within-occupation heterogeneity, this lack of data presents a dilemma.

Growth in earnings inequality and changes in the task content of occupations make this challenge more pressing. Although most research has focused on between-occupation earnings inequality, residual inequality is also substantial and increasing (Hunt and Nunn 2019; Mouw and Kalleberg 2010; Xie et al. 2016). Some of this within-occupation inequality may be due to variation in jobs and tasks (see, e.g., Avent-Holt et al. 2019; Wilmers 2020), but standard U.S. survey data do not allow for this kind of analysis. This leads to my first two research questions: How much variation in terms of job titles and task descriptions is present within occupational categories? What predicts within-occupation variation?

\section{PREDICTING OCCUPATIONAL SIMILARITY}

One hypothesis is that occupations with more social closure will tend to be less varied and more cohesive. Weeden and Grusky (2005) argue that occupations are coherent social communities, in which members hold shared identities. Members engage in closure strategies to limit the supply of labor and increase their earnings and prestige (Weeden 2002). Phenomena like occupational licensing, occupational training, and the use of employment intermediaries protect and harden occupational categories. Accordingly, occupations characterized by more social closure are likely to be more coherent in their terminology, with shared identity embodied in shared descriptions of work. Because occupations that have more closure tend to have higher average income, average education, occupational prestige, and unionization (Abbott 1988; Weeden 2002), I expect these factors will be positively associated with the similarity measures used in this study.

An alternative hypothesis is that higher-wage occupations will be more heterogeneous due to work becoming more specialized and complicated as average education increases. This line of reasoning is related to skill-biased technological change (SBTC). The SBTC hypothesis 
suggests technology is increasing returns to skills, generating inequality concentrated in the upper half of the skill distribution (Autor 2014; Fernandez 2001; Goldin and Katz 2008; Lemieux 2006). If technology is rapidly changing work in higher-status occupations, there might be a proliferation of job titles and complicated task descriptions in these occupations.

In addition, the literature suggests demographic heterogeneity will be positively related to within-occupation variation in terms of jobs and tasks. Scholars have suggested that job-title proliferation is a mechanism by which organizations preserve the gendered and racial division of labor (Baron and Bielby 1986; Bielby and Bielby 1989; Strang and Baron 1990). Strang and Baron (1990:481) theorize "within occupations, demographic heterogeneity may prompt privileged incumbents to mobilize and differentiate along racial or gender lines, fostering vertical and horizontal distinctions to preserve status." Indeed, in their study of job titles in California's state agencies, they find gender heterogeneity is positively associated with job-title proliferation (Strang and Baron 1990). This finding is consistent with historical case studies in which women are often explicitly confined to specific jobs within integrating occupations (Milkman 2016; Reskin and Roos 2009). Equal employment policies have made this process less obvious over time, but incumbents in more diverse occupations may continue to use job differentiation to try to minimize status threat and preserve hierarchies. Employers may facilitate this process as a means to divide workers and reduce solidarity (Glenn 2009).

Finally, within-occupation variation may be related to institutional environments. For example, Baron and Bielby (1986:568) predict that public sector organizations will proliferate job titles more than their private sector counterparts as a result of the "bureaucratization and rationalization of organizational life." On the other hand, rationalizing institutions may seek to standardize and streamline jobs, which could lead to fewer categories within occupations and greater homogeneity (Strang and Baron 1990). Unionization could also increase homogeneity by formalizing and standardizing jobs through union contracts and promoting the development of occupational communities among workers.

\section{Job Titles versus Task Descriptions}

It is important to note that the level and patterns of within-occupation variation depend on how the concept is measured. Surveys generally include two separate questions to categorize respondents into occupations: (1) "What kind of work do you normally do? That is, what is your job called?" and (2) "What do you actually do in that job? Tell me what are some of your main duties?" The answer to the first question provides a measure of job title; the second, task description.

One the one hand, job titles and task descriptions may convey the same information: what one does within the detailed division of labor. Therefore, we might expect that within-occupation similarity in job titles and tasks would be highly correlated and have the same basic relationship to different occupational covariates. Yet, there are potentially important differences between these concepts. For instance, job titles may be more likely to indicate status or identity. Employers may determine job titles based on hierarchies within organizations, and specialized job titles can serve as a form of compensation, or "hedonic wages" (Baron and Bielby 1986:568). Some employers even allow workers to craft their own job titles (Grant, Berg, and Cable 2014). On the other hand, task descriptions are likely to convey the activities workers literally carry out. ("What do you actually do in that job?") Thus, an occupational covariate could have different relationships with job-title versus task-description heterogeneity, depending on whether it is more closely tied to status and identity or tasks.

In addition to cross-sectional patterns of occupational heterogeneity, I also consider longitudinal patterns of both job-title and task-description heterogeneity. Macroeconomic changes suggest 
task heterogeneity is probably increasing over time. Technological innovations expand the range of products and services available, increasing the variety of tasks individuals might carry out. Consumers' preference for variety implies that the rate of tasks being added likely outpaces the rate of tasks being subtracted (Autor and Dorn 2013). Furthermore, evolving management strategies may change the distributions of tasks across workers, reducing some workers' turf while increasing others' (Wilmers 2020). In a neoliberal economy characterized by globalization and increased competition, employers are increasingly focused on "disruption" and "flexibility," which call for adaptability from the workforce (Snyder 2016).

Predictions around job-title heterogeneity are less clear. On the one hand, trends for job titles might follow trends for task descriptions. Technological change and the rise of the flexible economy might lead to more heterogeneity in job titles. However, the rise of occupational credentials and licenses could serve as a homogenizing force on workers' job titles (Kleiner and Krueger 2013).

Understanding the level and patterns of within-occupation heterogeneity is important given the centrality of occupations to theories of inequality, mobility, and work life. To the extent that occupational categories are largely internally homogeneous in terms of job titles and task descriptions, the results would lend support to the theory that occupations are cohesive and meaningful communities, and that the survey measures we use are effective at capturing these communities. It would also imply that stratification research should focus more on differences between occupations, rather than within occupations. To the extent that occupational categories are internally diverse and increasingly so, the results would suggest scholars should give more attention to dynamics within occupational categories and reevaluate the effectiveness of existing occupational classification schemes.

Furthermore, if occupations are very internally heterogeneous, it is critical to consider how occupations may conceal the depth and form of different kinds of stratification in the labor market. Occupations are often thought of as positions in a stratification system, like rungs in a ladder. To what extent do each of these rungs have their own set of differentiated positions? How might the inequalities we observe at higher levels of aggregation be reproduced at the micro level? To explore these questions, I turn to the case of gender segregation.

\section{OCCUPATIONAL SEGREGATION BY GENDER}

Occupational segregation by gender refers to the concentration of men and women in different occupations and has been the focus of much scholarly research (Charles and Grusky 2005; Jacobs 1989; Tomaskovic-Devey 1993a). Occupational segregation is critical because it is a major source of the gender pay gap (Budig 2002; Kilbourne et al. 1994; Mandel and Semyonov 2014; Petersen and Morgan 1995). Gender segregation is attributed to a combination of factors, including gender homophilous networks (Fernandez and Sosa 2005), employer sorting (Reskin and Roos 2009), self-selection (Fernandez and Friedrich 2011), discrimination and fear of discrimination (Correll, Benard, and Paik 2007; Petersen and Saporta 2004), early role socialization (Corcoran and Courant 1985), sex-role attitudes (Campero and Fernandez 2019), and gendered patterns of educational background and training (Charles and Bradley 2009; Dickson 2010; Turner and Bowen 1999).

Research on occupational segregation by gender began in the late 1960s, when women were entering the labor force at an increasing pace (Gross 1968). At the time, men and women were almost entirely segregated in different occupations. Recent estimates suggest segregation has declined by about 30 percent since 1970 (England et al. 2020). Yet, the occupational structure is still considered highly segregated by gender, even "hyper-segregated" (Charles and Grusky 2005). 
Almost all research in this area measures segregation in terms of occupational categories, at varying levels of aggregation. Because the classification system for detailed occupations has changed so much over time (as discussed earlier), scholars measuring trends in segregation are often forced to use more aggregated, time-invariant occupational categories. Measuring occupation at aggregated levels likely results in underestimates of segregation (Bielby and Baron 1984, 1986; Tomaskovic-Devey et al. 2006).

Bielby and Baron $(1984,1986)$ were the first to identify the extent to which measuring segregation at the occupation level obscures segregation at the job-title level, using data on 290 workplaces in California from 1964 to 1979. When they measured segregation based on seven major occupational groups, the Duncan Segregation Index $(D)$ was .37 , indicating 37 percent of men or women would need to be reclassified to equalize the distribution of men and women. However, when they used detailed occupations, $D$ increased to .75 . Finally, when the authors used job titles (over 10,000 in their sample), segregation was nearly complete, at .96. In fact, only 42 percent of the establishments in their sample contained any job titles shared by men and women. In a separate article, Baron and Bielby (1986) investigated how the proliferation of job titles imposed status gradations and gender distinctions in organizations. They found that men and women doing the same tasks were still assigned to different job titles.

Since that time, scholars of gender segregation have sometimes accounted for the lack of jobtitle data by inflating their estimates of segregation based on Bielby and Baron's findings (Tomaskovic-Devey et al. 2006). However, the labor market has changed dramatically in the intervening decades. Bielby and Baron found almost complete segregation at the level of job titles within workplaces. Clearly, that is no longer the case today. In addition, their sample was confined to a nonrepresentative set of workplaces in California. Since their study, there has been little research on job-title segregation (but see Tomaskovic-Devey 1993b), especially at the national level. This leads to my third research question: To what extent do occupations conceal gender segregation at the job-title level? The findings will shed light on the empirical question but will also demonstrate how aggregation can mask deeper forms of stratification. In addition, I improve on Bielby and Baron's method by taking into account how small units (job titles) influence measured segregation.

I also consider patterns of job-title segregation across major occupational groups and over time. Although Bielby and Baron (1986) found that job-title segregation was uniformly high across major occupational groups, it is reasonable to expect that job-title segregation has declined in some occupational groups more than others since that time. In terms of overall trends, job-title segregation may largely follow the same patterns as occupational segregation, with a steeper decline in the 1970s and 1980s, followed by a milder decline since 1990 (England et al. 2020). The same factors that decrease segregation at the occupation level, including women's increasing educational attainment, desegregation in fields of study, and policy initiatives, could also decrease job-title segregation. On the other hand, job-title desegregation may not have kept up with occupational desegregation. Research on individual professions finds that women often do not achieve the same levels within occupational hierarchies - a "glass ceiling" effect (Cotter et al. 2001; Hull and Nelson 2000). Additionally, women and men within the same occupations might tend to cluster in different specialties (see, e.g., Cech 2013; Chan and Anteby 2016). As described earlier, it is also possible that as women make inroads into occupations dominated by men, members of the dominant group differentiate themselves through job titles (Milkman 2016; Reskin and Roos 2009; Strang and Baron 1990). So, even as occupations become more integrated over time, job-title segregation could be more persistent.

I choose to focus on the case of gender segregation given its prominence in the literature and its demonstrated contribution to the gender wage gap. However, one could also investigate how 
occupations conceal stratification based on race, education, or other factors. Future research should attend to the myriad ways occupational categories may limit our understanding of the stratification process.

\section{RESEARCH DESIGN}

\section{Data}

I use data from the General Social Survey (GSS), a nationally representative survey of U.S. residents, from 1972 to 2018 . Through a sensitive data agreement with NORC at the University of Chicago, which oversees the GSS, I obtained access to individuals' verbatim replies to openended questions about occupations. ${ }^{3}$ These data are not publicly available because they may contain personally identifiable information.

During a face-to-face interview, respondents are asked (1) "What kind of work do you normally do? That is, what is your job called?" and (2) "What do you actually do in that job? Tell me what are some of your main duties?" (I refer to the responses to the first question as job name and the second as task description.) Respondents are instructed to provide answers based on their current or most recent occupation. For example, a respondent might say something along the lines of, "I am a sociologist" or "truck driver" for their job name, and "conduct research and teach students at [university]" or "I deliver packages across the country" for their task description. Interviewers record the responses, and coders at NORC use this information to assign each respondent to a detailed occupation code. The coders are professionally trained using materials from the Census Bureau and the Bureau of Labor Statistics. Coders also retroactively matched all verbatim responses from previous years to the 2010 occupational scheme.

In most datasets, occupational schemes are not harmonized across years. Each year of data is coded to the contemporaneous Census occupational scheme, which typically changes every decade, making longitudinal analyses difficult. Analysts get around this by using aggregated categories or using cross-walks to recode data from prior years to updated schemes, but these approaches result in either a loss of detail or increased measurement error.

Thus, the GSS provides two critical advantages. First, it includes the underlying text responses, which provide much more detail than is typically available. Second, the full dataset is matched to the same occupational scheme, enabling cleaner longitudinal analyses of detailed occupations.

In this study, I limit the GSS sample to nonmilitary individuals, with nonmissing data for occupation, whose interviews were conducted in English and who do not come from oversampling. ${ }^{4}$ The analytic sample contains 58,252 observations. Table 1 contains descriptive information at the individual level. I then collapse the dataset so each observation is a detailed occupation, with occupational characteristics computed based on the incumbents in the GSS. For the main analyses, I omit very small occupations (fewer than 10 observations) because they are not well represented in the data. The resulting occupation sample contains 435 detailed occupations representing 57,765 individuals (99 percent of respondents).

\section{[Table 1 about here]}

Although all respondents with nonmissing occupation originally provided descriptions of their work to GSS interviewers, some verbatim data are missing because the original survey files were not recovered by the GSS (NORC at the University of Chicago 2016). Specifically, 5 percent of respondents with nonmissing occupation are missing the original text for both job 
name and task description $(N=2,878)$. The missing data are heavily concentrated in a few specific years in the 1970s and 1980s. In sensitivity tests, I eliminate years with a lot of missing data. In addition, 4 percent of individuals with nonmissing job name are missing task description $(N=2,302) .{ }^{5}$ In sensitivity tests, I replace missing task descriptions with the values for job name.

An important possibility to consider is that variation in how respondents describe their work is due to variation in the way people speak, rather than actual variation in job names and tasks within occupations. As a hypothetical example, if women give more detailed responses to survey questions than men do, this could lead me to conclude that men and women are segregated into different job titles, when in fact, men just use more general language to talk about the same job, or vice versa. Another plausible possibility is that people who are more educated use more varied language in their descriptions simply because they have a larger vocabulary, not because their work is actually more heterogeneous.

Although I cannot fully rule out these possibilities, I explore them by using another set of variables in my data: questions about spouses' and parents' occupations. After answering two questions about their own work, respondents answer the same questions (job name and task description) for their spouse, if they have one; for their father; and, in some years of the GSS, their mother. Therefore, I can examine how gender and education are associated with the length of responses given by respondents when talking about work that is not their own. I run a series of linear regressions with the length of responses (number of words) of the job names and task descriptions for spouses, fathers, and mothers as the dependent variables, and either gender or education (college versus non-college) as the independent variables. I control for the occupation being described.

Results of these tests are in Appendix B. For gender (Table B1), I find that women do tend to give slightly longer responses than men, but the magnitude of the difference is small (about half of one word for task descriptions, which tend to be around 12 words in length), and the difference is not statistically significant for job names for spouses and mothers (but it is significant for fathers). For education (Table B2), I find almost no association between education and length of responses after controlling for the occupation being described. The only exceptions are for job names for fathers and task descriptions for spouses, where there are small negative associations between college attendance and length of response. Although these tests do not prove that men and women and college and non-college respondents speak in the same way, they provide some assurance respondents are not answering questions about work in dramatically different ways in terms of length.

\section{Measuring and Predicting Occupational Similarity}

To address my first two research questions, I estimate the level of similarity within occupations and predict similarity based on occupation-level covariates. I define a heterogeneous (low similarity) occupation as one in which workers describe their jobs or tasks in a variety of different ways, using different terms. Homogeneous (high similarity) occupations are characterized by similar or identical job names or descriptions of tasks. When I discuss "occupational heterogeneity" or "occupational similarity," these concepts are operationalized based on job names or task descriptions, as recorded by GSS interviewers.

The text responses are relatively short. The mean number of words for verbatim job names is 4.03, and the mean number of words for verbatim task descriptions is $12.11 .^{6}$ I preprocess the text by removing punctuation, numbers, and excess whitespace and lowercasing all letters. For the main analyses, I also remove stopwords, correct misspelled words, and lemmatize the text. ${ }^{7}$ In sensitivity checks, I conduct the analyses without these modifications (see Appendix A). 
I measure occupation-level similarity in terms of the average cosine similarity between pairs of observations within detailed occupations. Cosine similarity is a commonly used measure in computational text analysis that indicates the level of similarity between two documents based on unordered word usage and irrespective of the length of the documents (Manning et al. 2008). Each document is represented as a vector in a high-dimensional space. Cosine similarity is the cosine of the angle between the two vectors. The measure ranges from 0 to 1 , with 0 indicating the documents use none of the same words, and 1 indicating the documents use the exact same words in the same proportions. In my case, the "documents" comprise either job names or task descriptions. I calculate the cosine similarity between each pair of respondents within a fourdigit occupation and then take the average pairwise cosine similarity to produce a similarity index $C$ for each occupation.

$$
\begin{aligned}
& \operatorname{sim}\left(x_{i}, x_{j}\right)=\cos (\theta)=\frac{x_{i} \cdot x_{j}}{\left\|x_{i}\right\|\left\|x_{j}\right\|} \\
& C=\frac{\sum_{i=1}^{P} \sum_{j=1, j \neq i}^{P} \operatorname{sim}\left(x_{i}, x_{j}\right)}{|P|(|P|-1)}
\end{aligned}
$$

<indent here>In Equation 1, $x_{i}$ and $x_{j}$ are vectors, each representing the text response of a survey respondent. In Equation 2, $P$ represents the number of observations for an occupation. I calculate $C$ for each occupation in terms of job names and, separately, task descriptions.

As a simple, hypothetical example, suppose the data contained just three observations for the occupation postal workers, A, B, and C, with the following task descriptions: "deliver mail," "deliver mail," and "sort, deliver mail." The cosine similarity between observations A and B is 1 , as they use identical words in the same proportions. The similarity between $\mathrm{A}$ and $\mathrm{C}$ is .82 , and the similarity between $\mathrm{B}$ and $\mathrm{C}$ is also .82 . The average pairwise similarity, $C$, for this occupation based on task descriptions would therefore be .88 .

One potential limitation of cosine similarity is that it does not account for word meaning. For the purposes of this study, I am interested in any word differences because I do not want to assume that similar-seeming words do not have different connotations to incumbents. However, if highly interchangeable words, such as "taxi" and "cab," are concentrated in certain occupations, then cosine similarity could be misleading. To address this concern, I conduct a sensitivity test where I replace cosine similarity with a metric that accounts for semantic similarity. The measure is called Word Mover's Distance (WMD) (Kusner et al. 2015; Pele and Werman 2009), and it is gaining traction within the social sciences (e.g., Stoltz and Taylor 2019). This distance function relies on word embeddings that represent words as semantically similar based on local co-occurrences of words in a large training corpus (Kozlowski, Taddy, and Evans 2019; Mikolov et al. 2013). Words are represented as vectors in a continuous $n$ dimensional space, such that words closer together mean similar things. "The WMD distance measures the dissimilarity between two text documents as the minimum amount of distance that the embedded words of one document need to 'travel' to reach the embedded words of another document" (Kusner et al. 2015:957). Thus, semantically similar texts will have lower distances, even if they use different words. Using WMD, "taxi driver" and "cab driver" are more similar than "taxi driver" and "bus driver," even though the cosine similarity between these pairs is the same. To implement WMD, I use pre-trained, normalized word embeddings based on Google News. These Word2Vec embeddings use billions of words from Google News as the training corpus. I use the additive inverse of the WMD metric to make it comparable with cosine similarity. 
After calculating the cosine similarity measure, $C$, for each detailed occupation, I conduct a series of linear regressions to predict similarity based on a vector of occupation-level covariates. I include variables for occupational prestige (as measured by the 2010 socioeconomic index, or SEI), education, income, unionization, and proportion public sector. I also include demographic characteristics, specifically median age, proportion men, and proportion White, and quadratic terms for gender balance (proportion men multiplied by proportion women) and racial balance (proportion White multiplied by proportion non-White). All covariates are drawn from the GSS. Other datasets may contain more comprehensive information on occupational characteristics, but using GSS data allows me to generate covariates for the 2010 occupational scheme using data from 1972 to 2018.

\section{Measuring Job-Title Segregation by Gender}

In the next stage of the analysis, I measure segregation by gender at different levels of aggregation. First, I measure the level and trend in segregation based on the five major occupational groups into which the Census organizes detailed occupations: "management, professional, and related occupations," "service occupations," "sales and office occupations," "natural resources, construction, and maintenance occupations," and "production, transportation, and material moving occupations." Then, I run the same analysis for several hundred detailed occupations from the 2010 scheme. Finally, I measure segregation based on job titles.

My measure of job title comes from matching the verbatim job names in the GSS with job titles in the Census's Alphabetical Index of Industries and Occupations. These indices are developed and continuously updated to classify respondents in the Census's demographic surveys (U.S. Census Bureau 2019). I use the 2010 index, which contains over 30,000 job titles, each matched to the 2010 occupational scheme. To match verbatim job names to titles, I first preprocess the index of job titles by removing punctuation, stopwords, excess whitespace, and extraneous strings (e.g., "not specified" or "bachelor's degree or higher") and lemmatizing the text. I calculate the edit distance between each verbatim job name and the list of titles associated with the respondent's four-digit occupational code and identify the match with the shortest distance. Edit distance is the number of character insertions and deletions required to transform one string into another. ${ }^{8}$ Essentially, my goal is to reverse-engineer the process by which coders classify individuals into occupations. Their process involves starting with the individual's verbatim response, finding the best match in the index of titles, and then identifying the corresponding four-digit occupation code. I have the verbatim responses and the four-digit codes, which I use to derive a job title for each individual. Although this procedure introduces measurement error when there are imperfect matches, measuring segregation with job titles is preferable to using the original verbatim job names because the Census's job titles are standardized and do not include potentially extraneous language that respondents might include in their verbatim descriptions.

To measure segregation, I calculate the Duncan Segregation Index $D$ (Duncan and Duncan 1955 ) at three levels of aggregation for each decade from the 1970s to the 2010s. (This measure is also called the "Index of Dissimilarity," but I refer to it as the Duncan Segregation Index for the sake of clarity.) For a given set of categories, $D$ indicates the proportion of men (or women) who would have to switch categories in order for the distribution of men and women across categories to be equal. The measure ranges from 0 to 1 , with 0 indicating the ratio of men to women in each category is equal to the ratio of men to women in the overall sample, and 1 indicating men and women are completely segregated into different categories.

$$
D=\frac{1}{2} \sum_{i=1}^{n}\left|\frac{m_{i}}{M_{T}}-\frac{w_{i}}{W_{T}}\right|
$$


<indent here>In Equation 3, $n$ refers to the number of categories (for major occupations, detailed occupations, or job titles), $m_{i}\left(w_{i}\right)$ refers to the number of men (women) in category $i$, and $M_{T}\left(W_{T}\right)$ refers to the total number of men (women) in the data. The Duncan Segregation Index has been criticized, and other measures exist (e.g., Charles and Grusky 2005). However, I use this measure given its continued prevalence in the literature and to replicate Bielby and Baron (1986). Future research should examine alternative segregation measures.

A challenge in measuring job-title segregation with the GSS is sample size. Even pooling across years, I have few observations for smaller occupations, and at the level of job titles (of which there are over 10,000 in my data), the data are extremely sparse, leading to substantial noise in my analysis of segregation. With small unit sizes, the expected level of segregation under the null hypothesis of random allocation increases. (This is one of the critiques leveled against Bielby and Baron [1986]); see Carrington and Troske [1997].) To address this concern, I use permutation tests to simulate the range of possible $D$ values under the null hypothesis in which there is no unmeasured segregation at higher levels of aggregation, and then I compare the distribution of simulated $D$ to the point estimate. This procedure allows me to identify whether there is statistically significant segregation at the more detailed levels that is not captured at the more aggregated levels. Appendix $\mathrm{C}$ outlines this procedure.

I examine patterns of job-title segregation over time and across major occupational groups. I also consider the relationship between occupational similarity (based on cosine similarity for job names, as described previously) and job title-level segregation.

\section{EMPIRICAL RESULTS}

\section{Level and Trend of Similarity}

Results indicate a substantial range of within-occupation similarity in terms of both job names and task descriptions. The average cosine similarity $(C)$ has a mean of .23 and a standard deviation of .16 for job names, and a mean of .10 with a standard deviation of .07 for task descriptions. As a point of comparison, a random sample of 150 individuals from the GSS, across any occupation and any year, has an average cosine similarity of .01 for job names and .01 for task descriptions. It is not surprising that, in general, occupations are more similar in terms of job names than in terms of task descriptions. Respondents tend to give more detailed descriptions of their tasks, leaving more room for variation. What may be surprising is the amount of heterogeneity present even within detailed occupations. As shown in Figure 1, both job-name and task-description similarity are right-skewed, with few occupations that are internally homogeneous.

\section{[Figure 1 about here]}

Table 2 provides examples of occupations that are very internally similar and dissimilar based on the two variables. Among occupations with at least 50 observations, the most similar ones in terms of job name are "pharmacists," "travel agents," "tellers," "bus drivers," and "roofers." This set of occupations includes a range of both high- and low-status and licensed and nonlicensed occupations. The least similar occupations are "miscellaneous entertainment attendants and related workers," "crushing, grinding, polishing, mixing, and blending workers," "weighers, measurers, checkers, and samplers, recordkeeping," "other installation, maintenance, and repair workers," and "compliance officers." This latter set of "catch-all" occupations mostly have long, complex names, apparently combining smaller, more detailed categories.

[Table 2 about here] 
The set of most and least similar occupations as measured by task descriptions is somewhat different. "Postal service mail carriers," "postal service mail sorters, processors, and processing machine operators," "dishwashers," "hairdressers, hairstylists, and cosmetologists," and "painters, construction and maintenance" are the most similar. "Business operations specialists, all other," "office and administrative support workers, all other," "compliance officers," "miscellaneous entertainment attendants and related workers," and "management analysts" are the least similar. Here we see that the more similar occupations are generally lower status than the dissimilar examples.

It is notable that the least similar occupations in the dataset are not much more internally similar than a pseudo-occupation based on a random sample of individuals across any occupation. For example, the occupation "business operations specialists, all other" has a task-description similarity score of .02, compared to the pseudo-occupation's score of .01 .

Figure 2 plots job-name and task-description similarity and shows a loose positive correlation. As expected, occupations that are more similar in terms of job names are generally also similar in terms of task descriptions. However, we do see a set of occupations that are internally homogeneous in terms of job names but still have a wide variety of task descriptions, and vice versa. Thus, it appears that job names and task descriptions are not interchangeable measures but do indeed represent different social processes.

\section{[Figure 2 about here]}

How has within-occupation similarity changed over time? Figure 3 plots the mean similarity (weighted by occupation size) over five decades for job names and task descriptions. Similarity declines over time for both job name and task description, indicating occupations have become more heterogeneous over time on these dimensions. The trend over time should be interpreted with caution, due to changes to the GSS. In 2002, the GSS switched from paper and pencil interviewing to computer-assisted personal interviewing, which may have led interviewers to write down more or less detail than previously. Nevertheless, the downward trend is evident before 2002 and comports with expectations based on the changing nature of work, with technological advances translating into new tasks and job titles.

\section{[Figure 3 about here]}

\section{Predicting Similarity}

I next predict within-occupation similarity with a series of linear regressions. Table 3 shows occupation-level descriptive statistics, unweighted and weighted by occupation size. Tables 4 , 5 , and 6 show the regression results. In Table 4, Models $1-3$, job-name similarity is strongly associated with occupational prestige. An increase of 1 in the scaled SEI is associated with an increase of .187 in job-name similarity. (As mentioned, the similarity score can range from 0 to 1.) The second model adds demographic covariates for occupational proportion men, gender balance, proportion White, racial balance, and median age. The third model includes proportion unionized, proportion public sector, and occupation size. The coefficient on SEI is largest in the final model, at .269, and highly statistically significant. Proportion men and gender balance are significant negative predictors of similarity, all else equal, indicating that gender heterogeneity is associated with job-name heterogeneity. By combining the linear and quadratic effects in Model 3, job-name similarity is estimated to be lowest when occupations are 55 percent men. In addition, occupations characterized by less public sector representation have higher job-name similarity, all else equal. 


\section{[Table 3 about here]}

In general, these findings are consistent with expectations based on prior research. Higher SEI occupations, which tend to have more licensing and educational requirements and are characterized by more professionalization and occupational closure, are more internally similar based on job names (Abbott 1988; Weeden 2002). Occupations that have a more even mix of men and women tend to be less internally cohesive (Strang and Baron 1990). The finding that proportion public sector is negatively associated with similarity perhaps reflects bureaucratic complexity (Baron and Bielby 1986) or unique naming conventions across jurisdictions. It is somewhat surprising that unionization and racial composition are not significant predictors of similarity, although this may be an artifact of pooling across years, during which occupations underwent transitions. (I return to this possibility below.)

In Models 4-6 of Table 4, I predict $C$ in terms of task descriptions, instead of job names. Interestingly, the coefficient on SEI is negative instead of positive, and significant. In Model 6 , with all covariates included, an increase of 1 in the scaled SEI is associated with a decrease of .048 in task-description similarity. This relationship may reflect the increased complexity and specialization of tasks as skill requirements increase. Proportion men and gender balance remain significant (task similarity is estimated to bottom out at 59 percent men). The remaining covariates are not significant in this model.

\section{[Table 4 about here]}

How can it be that higher-status occupations have less heterogeneity in terms of job names but more heterogeneity in terms of task descriptions? The fact that these measures do not move in tandem lends further support to the occupational closure hypothesis. Without incumbents' efforts to draw boundaries around occupations through naming conventions and to cultivate occupational communities, it is unlikely we would see this pattern. In other words, if job names reflected the actual work performed, we would not expect to see this difference. Higher-status occupations, with their increased task variety, would have more heterogeneous titles. Instead, we see evidence that social closure may be successful in reducing title heterogeneity within occupations.

Table 5 presents the full models from Table 4, but uses median log income (Models 1 and 2) and occupational education (Models 3 and 4) instead of SEI as the primary predictors. The results are largely consistent. We see a strong positive relationship between occupational income (or education) and job-name similarity, and a pronounced negative relationship between occupational income (or education) and task-description similarity. In all models, gender balance is strongly associated with less similarity. Proportion public sector is not significant.

\section{[Table 5 about here]}

In the regressions presented thus far, each observation is an occupation that pools observations from the entire time period from 1972 to $2018(N=435)$. The benefit to this approach is that it increases the number of observations per occupation, reducing noise in my measures of similarity. But it also ignores changes over time in occupational characteristics. To address this issue and account for changes in occupational composition over time, I run regressions where each observation is an occupation-decade $(N=2,101)$. The results (Table 6) are largely consistent with the pooled models. SEI is highly statistically significant (positive for job name, negative for task description). Gender balance and proportion public sector are negatively related to both measures of similarity. However, for job-name similarity, racial composition and unionization also become significant predictors. Racial composition appears to be a mostly linear relationship such that proportion White is positively associated with job-name similarity. 
Further research is needed to identify any causal relationship, but this finding suggests racially diverse occupations may be characterized by more internal differentiations, perhaps elevating the status of White incumbents (Tomaskovic-Devey 1993a). In addition, proportion unionized also has a significant positive relationship to job-name similarity. Consistent with social closure theory, unions may act as a homogenizing force, imposing coherence on job names; alternatively, internally similar occupations may be more easily unionized.

\section{[Table 6 about here]}

In sensitivity tests (Appendix A), the central findings regarding the positive association between SEI and job-name similarity, and the negative association between gender balance and (jobname and task-description) similarity are robust to a variety of sample restrictions and model specifications, including using Jaccard similarity or Word Mover's Distance ${ }^{9}$ instead of cosine similarity (Table A1), excluding individuals who are not currently working or who are selfemployed (Table A2), including very small occupations (Table A3), using alternative text preprocessing strategies (Table A4), eliminating years with more than 10 percent missing data for job name or eliminating years before 1990 (Table A5, Models 1-4), replacing missing verbatim task descriptions with verbatim job names (Table A5, Models 5 and 6), excluding NEC ("not elsewhere classified") occupations (Table A6, Models 1 and 2), and controlling for occupation name length (Table A6, Models 3 and 4). Furthermore, the coefficients on SEI when predicting task-description similarity and the coefficients on public sector are always negative, although not always statistically significant.

In an additional sensitivity check, I weight for occupation size. In the main regressions, I treat all occupations equally because I am interested in predicting occupational rather than individual characteristics, and I do not want the largest occupations to dominate the results. (The distribution of occupation size is highly skewed.) However, it is interesting to consider the individual worker experience, which is better represented by weighted regressions. As shown in Table A7, the results are mostly consistent, but the magnitude and significance of the coefficients change. SEI remains a highly significant predictor of job-name similarity, but it is no longer significant in terms of task-description similarity. Instead, unionization becomes significant, positively predicting both job-name and task-description similarity. This difference is mainly due to the very large occupations that have a history of significant unionization, such as "elementary and middle school teachers," "secondary school teachers," and "driver/sales workers and truck drivers." In addition, racial composition becomes a significant predictor of task-description similarity, driven in part by large, racially diverse occupations like "maids and housekeeping cleaners" and "cooks," which have relatively high task-description similarity.

So far, I have described the patterns of occupational similarity, as measured by job names and task descriptions. Taken together, results indicate that higher-ranking occupations (in terms of prestige, education, or income) tend to be more homogeneous in terms of job names but more heterogeneous in terms of task descriptions. Furthermore, gender composition strongly predicts similarity, such that occupations with a more even mix of men and women are more internally heterogeneous in terms of both job names and task descriptions. Proportion public sector is associated with increased heterogeneity, whereas unionization is associated with increased homogeneity in some models. More generally, we see that some occupations are very coherent and others are highly heterogeneous, and occupations appear to be becoming less internally similar over time.

Why does occupational similarity matter? One important potential implication is that occupational categories may conceal inequality and stratification, particularly if they are highly internally differentiated. In the next section, I show how measuring gender segregation in terms of job titles reveals significant hidden segregation within occupations and over time. 


\section{Occupational Segregation by Gender}

I calculate occupational segregation by gender at three different levels of aggregation: major occupational groups, detailed occupations, and job titles. Pooling across all years, the overall segregation index $(D)$ is .30 for the five major occupational groups. This indicates that in order for men and women to be equally represented across the five groups, 30 percent of men (or women) would have to switch to a different major occupational group. Zooming in to the detailed occupation level, the picture of segregation changes dramatically: $D$ increases to .56 . Finally, at the most detailed level (job titles), $D$ increases to .68, suggesting more than twothirds of men (or women) would have to change job titles to equalize the gender distributions. Some of the measured job title-level segregation may be due to small sample size, but permutation tests (Appendix C) allow me to reject the null hypothesis that the increase in jobtitle segregation is due to random allocation.

Table 7 shows the segregation indices for each of the five major occupational groups. (I model this table on the one presented by Bielby and Baron [1986:776].) In the full sample, more than 17,000 workers are in "managerial, professional, and related occupations," and roughly half of those individuals are men. This major occupational group contains 189 detailed occupations, ranging from "food service managers" to "lawyers" to "sociologists," and 2,993 unique job titles. Although this major occupation is relatively balanced in terms of gender, we see substantial segregation at the detailed occupation level (.46), and even more segregation at the job-title level (.59). Thus, a very different picture of gender segregation emerges depending on the level of aggregation. Significance daggers indicate the results of the permutation tests. All the segregation indices are highly significant, except for the job-title segregation index for "natural resources, construction, and maintenance occupations." This major occupation is heavily dominated by men ( 93 percent), so there is little additional segregation captured at the job-title level.

\section{[Table 7 about here]}

Figure 4 shows how the level of aggregation changes our understanding of the time trend in gender segregation. At the level of major occupation groups (bottom line), the trend is mildly declining, with a slight uptick in the 2000s. At the level of detailed occupations (middle line), the trend most closely resembles those found in other research, with a steeper decline in the 1970s and 1980s, followed by a milder decline. At the level of job title, however, we see a leveling off in the most recent period, and a widening in the gap between job-title and occupation-level segregation. Further research is needed to verify this trend, but these findings suggest a troubling possibility, where improvements in occupation-level gender segregation over time may mask stagnating segregation at the job-title level. This finding is consistent with the literature on the stalled gender revolution, which finds that progress toward gender equality has slowed on a variety of indicators (England 2010; England et al. 2020). The increase in jobtitle heterogeneity over time, as presented in the previous section, could help explain this trend, especially if job titles are indeed a mechanism to differentiate men and women within occupations.

\section{[Figure 4 about here]}

I also consider cross-sectional variation in the job-title segregation index. Although it is not straightforward to compare the Duncan Segregation Index across occupations that vary in size and demographic composition, especially when pooling across years, the patterns presented suggest dramatic variation in the amount of segregation hidden within occupations. Figure 5 plots the proportion of men in each occupation with the job-title segregation index. In general, 
occupations with more men tend to have more job title-level segregation, but across all occupational gender compositions we see that some occupations have substantial hidden job title-level segregation, and others have very little.

\section{[Figure 5 about here]}

To provide some examples, the occupation "bus drivers" contains 43 percent men in this sample. However, the job-title segregation index is .41, indicating 41 percent of individuals would have to switch job titles for the gender composition of job titles to equal the gender composition of the occupation as a whole. It turns out that women are disproportionately represented in the job title "school bus driver," and men are overrepresented in other kinds of bus driving jobs. As another example, "postsecondary teachers" appears to be relatively balanced, with 52 percent men in the occupation. Yet, the occupation contains significant job title-level segregation. Some of the job titles in this category with disproportionate women incumbents include "teaching assistant," "assistant professor," and "nursing instructor." Third, the occupation "butchers and other meat, poultry, and fish processing workers" is 63 percent men; however, zooming in to the job-title level, men dominate the job titles "butcher" and "meat cutter," whereas women are concentrated in other job titles associated with factory work.

On the other hand, some occupations have little to no meaningful job-title segregation. For example, the occupation "postal service mail clerks" is 52 percent men. The job-title segregation index is .14, but this score is below what we would expect if individuals were randomly assigned to job titles within occupations (based on the 50th percentile of permutation test results). Thus, it appears this occupation is well integrated at the job-title level. Other examples of integrated occupations include "lodging managers" and "purchasing agents, except wholesale, retail, and farm products." Both occupations have nearly equal representation of men and women (49 and 54 percent men, respectively) and no significant job title-level segregation.

Finally, the amount of job-title segregation appears to be strongly associated with the level of job-name similarity, as measured in the previous section. Figure 6 shows a pronounced negative correlation, indicating that occupations that are more internally similar in terms of job names tend to have less job-title segregation. This relationship holds after controlling for the covariates used in this study.

\section{[Figure 6 about here]}

To summarize, estimating job title-level gender segregation - an exercise typically impossible with standard survey data - demonstrates how occupational categories conceal meaningful levels of segregation, variation across the occupational spectrum, and potentially divergent trends over time. Occupations that are more internally heterogeneous appear to have more scope for hidden gender segregation.

\section{LIMITATIONS}

The GSS verbatim text data used in this study offer an unprecedented window into occupational categories, with rich, nationally representative detail on job names and tasks across five decades, all matched to the 2010 occupational scheme. Yet, the data are imperfect, and findings from this study should be interpreted with a few limitations in mind.

First, it is important to acknowledge that self-reports of occupation may be unreliable. Prior studies have found substantial differences between employers' and employees' reports of individuals' occupations, especially at more detailed levels (Mathiowetz 1992; Mellow and Sider 1983). Mellow and Sider (1983) compared responses to the CPS with employer records 
and found only 80 percent agreement based on one-digit major occupational categories and 58 percent agreement at the three-digit occupation level. It is unclear to what extent the disagreement is due to respondent error, employer error, interviewer error, or coder error. When interpreting the findings from this article, it is important to keep in mind that these are selfreports, as recorded by interviewers, and that a study based on employer-provided data might reveal different (although not necessarily more accurate) results.

Even so, I argue that self-reported job names and task descriptions still reveal important heterogeneity in terms of employees' understandings of their own work. Given the prevalence of self-reports in many important surveys, such as the ACS and CPS, it is important to understand this kind of data. Furthermore, if self-reported occupation is highly correlated with, for instance, the occupations reported in résumés to future employers, then it could have important implications for intragenerational mobility and inequality. Additionally, understanding how incumbent workers talk about their jobs and tasks provides valuable information about the amount of cohesion within occupations. If occupations should be thought of as "micro-classes" (Weeden and Grusky 2005), then we would expect the way workers talk about their jobs and tasks to reflect their membership in and identity with a cohesive community.

Second, the data and methods used in this study may underestimate gender segregation, relative to the procedure used by Bielby and Baron (1986), which measures segregation based on employer-provided job titles, within firms. My design uses the Census's index of job titles, based on self-reported job names, and does not take into account workplaces. There are at least three reasons why my procedure might lead to lower estimates of gender segregation. First, it is reasonable to expect respondents would provide a more general job name to a GSS interviewer than the official job title written in their employment contract. Second, the procedure I use to match verbatim job names from the GSS to the Census's index of job titles likely introduces measurement error. Although the index is intended to be comprehensive, some of the job names provided by GSS respondents do not match well with the Census's list. Rather than adding titles to the Census's list, I select the closest match based on edit distance, which likely underestimates the total number of actual job titles as well as the level of job title-level segregation. Third, and relatedly, I use job titles as the category for the segregation calculation, rather than job titles within firms. If men and women with the same job titles tend to work in different establishments, gender segregation is underestimated. Because the growth in withinoccupation inequality is generally attributed, at least in part, to firm-level differences (Abowd, McKinney, and Zhao 2018; Barth, Davis, and Freeman 2018; Card et al. 2018; Song et al. 2018), the ideal dataset would include both job title and firm information, as in Bielby and Baron (1986) (although their data were limited to a nonrepresentative set of firms over a relatively short time span).

Third, the sample size for some of the occupations is small in the GSS. I address this limitation in various ways, by pooling across decades in some of the models, by excluding very small occupations, and by implementing permutation tests for my segregation measures. Yet, these are imperfect solutions, and the point estimates for smaller occupations are probably noisy.

Finally, the patterns observed in this study are descriptive. Future research should delve into both the causes and consequences of within-occupation variation and job title-level segregation.

\section{DISCUSSION}

At the beginning of this article, I argued that occupations are central to the study of inequality, mobility, and work life, but the categories that quantitative researchers rely on are based on an idiosyncratic process by the U.S. Census Bureau and conceal potentially important variation. 
The lack of detailed information about jobs and tasks hinders our understanding of the occupational structure and may mask deeper forms of inequality. I drew on a novel dataset to elucidate variation within occupations: the verbatim responses provided by respondents to the GSS when asked about their current or most recent occupation. These data allowed me to estimate the level of within-occupation similarity in terms of job names and task descriptions and to examine the factors associated with increased similarity. I also demonstrated how aggregation conceals patterns of gender segregation that are typically unobserved.

First, I found that occupations do indeed conceal a large amount of heterogeneity, both in terms of job names and task descriptions. The words and terms people use to describe their work and their duties vary considerably. However, that variation itself also varies across the labor market. Some occupations, it turns out, are highly cohesive. Most travel agents, tellers, and pharmacists describe their job names in very similar ways as their occupational peers. And postal workers, hairdressers, and bus drivers use similar sets of words to describe their tasks. Yet, for every person classified as a pharmacist, there is someone classified as a "laborer and freight, stock, and material mover (hand)" or a "textile, apparel, and furnishings worker (all other)." And although most postal workers may share descriptions of their tasks (e.g., "delivering," "sorting"), "business operations specialists, all other" and "compliance officers" hardly use any of the same words to describe their duties. The distributions of both job-name and taskdescription similarity are right-skewed, and the amount of heterogeneity within detailed occupations is remarkable.

Second, I demonstrated that there are comprehensible patterns in the kinds of occupations that are more or less internally similar. I provided descriptive evidence that occupations that rank higher in terms of prestige, average educational attainment, and average income are more internally similar in terms of job titles, but less internally similar in terms of task descriptions. These divergent patterns are striking and perhaps reflect the social construction of occupational communities through closure strategies in higher-status occupations. Occupations that have licensing or educational requirements and that limit labor supply are probably more cohesive in terms of titles. Perhaps people in these occupations feel more of a sense of solidarity or community with their fellow incumbents. And perhaps benefits flow to these individuals because their job titles are easily recognizable, shared with more people, and clearly convey a set of skills and experiences, even though the underlying tasks may be highly varied. On the other end of the spectrum, lower-status occupations are characterized by relatively less job-title similarity and more task-description similarity. Thus, incumbents may be doing similar kinds of work but are not calling their jobs by the same names.

In some models, I found suggestive evidence that unionization and occupational similarity are positively correlated. Although there may be omitted variables, the results suggest unions may have a homogenizing effect on occupational titles and tasks, or, alternatively, occupations that are more internally similar may be more easily unionized. The link between within-occupation similarity and worker solidarity warrants further exploration. I also found a negative correlation between proportion public sector and occupational similarity, consistent with the notion that highly bureaucratized settings will proliferate job titles (Baron and Bielby 1986).

Furthermore, I found a pronounced, nonlinear relationship between occupational similarity and gender composition. Occupations with 55 and 59 percent men are predicted to be the most internally heterogeneous in terms of job names and task descriptions, respectively. Although the analysis is not causal, results are consistent with the theory that job differentiation may be a mechanism to preserve inequality and hierarchy within diversifying occupations (Reskin and Roos 2009; Strang and Baron 1990). 
Finally, I demonstrated how measures of gender segregation in the labor market are highly sensitive to the level of aggregation. Depending on the level used, a different picture emerges of how integrated men and women are in the labor market. Furthermore, the time trend in job-title segregation plateaus in the most recent decade, a novel phenomenon not evident at the occupation level. This trend is consistent with the notion of a stalled gender revolution (England 2010; England et al. 2020) and cautions us that progress at the level of occupations may be stymied by less visible forms of stratification. Although job-title segregation is necessarily higher than occupation-level segregation, I used permutation tests to show there is a wide range of job title-level segregation: some occupations are well integrated at the job-title level, whereas others are deeply segregated. Occupations with lower job-name similarity are shown to have more scope for job-title segregation.

I used the case of gender, but a similar story may be true for race, education, and other worker characteristics. What are the levels and patterns of stratification hidden by categorization? Even within detailed occupations, heterogeneity and segregation is striking. The consequences of this phenomenon become apparent when we look at how the U.S. Equal Opportunity Commission monitors the demographic composition of firms. EEO-1 surveys collect data from employers on the gender and racial composition of just ten job categories.

The findings from this study have several implications for future research. First, the results have important implications for the study of earnings inequality. Although the earnings measures in the GSS are relatively crude, preliminary analyses indicate the measures of occupational similarity presented in this study are negatively associated with the variance of log income, after controlling for the covariates used in this study. Future research should interrogate the nature of the relationship between job-name and task similarity and earnings inequality.

Future research should also investigate the causes and consequences of job-title segregation. Gender segregation has declined at both the occupation and job-title levels, but this article demonstrates there is still much differentiation we do not fully understand. What are the implications of men and women concentrating in different job titles within the same occupational categories? To what extent might job-title segregation contribute to the gender pay gap, reduce solidarity, divide workers, and keep women separated in lower-status or lowerquality jobs? Why do we see job-title segregation in some occupations more than others? Is it due to persistent gender essentialist tendencies, employer or incumbent efforts to divide workers, or other factors? It is also important to consider whether the quality of segregation has changed over time. For example, are job-title differences primarily horizontal or vertical? How have changes in the organization and nature of work altered what job-title segregation means for workers' experiences?

Next, the measures of occupational heterogeneity presented can be helpful for understanding the challenges associated with occupational coding. A growing literature indicates that occupational coding is less reliable than previously thought, in that independent coders often do not assign respondents to the same occupations (Conrad, Couper, and Sakshaug 2016; Kim et al. 2020; Speer 2016). This phenomenon is less surprising when we observe the high levels of within-occupation heterogeneity in job names and task descriptions, which are the bases for occupational coding. Indeed, the rate of inter-coder mismatch appears to vary across the occupational spectrum in ways that align with my findings. For example, using the Korean Social Survey, Kim and colleagues (2020) find that the broad category of managerial occupations has the lowest match rate between independent coders, and professional/semiprofessional occupations have the highest match rate. My findings are consistent, in that jobname similarity is relatively low within managerial occupations (.19 unweighted average for occupation codes 10 to 950 ), but relatively high for professional occupations (.28 for occupation codes 1000 to 3540 ), compared to an average of .23 across all occupations. 
Intuitively, more heterogeneous occupations are harder to classify; occupations that are more cohesive and characterized by more social closure are easier to classify. The implication is that occupational categories cannot all be interpreted in the same way.

Furthermore, my analysis of the GSS data offers a proof-of-concept for using open-ended text responses from large-scale surveys to uncover important information about occupations.

Replicating this study on other survey datasets and with other occupational schemes would be worthwhile, both in the United States and in other countries. It is critical to protect personally identifiable information that may appear in open-ended responses. However, we increasingly have the capacity to securely analyze these data through specialized workspaces.

This study also calls for increased attention to within-occupation heterogeneity more generally. Measuring this concept with other kinds of data, such as employer surveys or job

advertisements, would help confirm the robustness of the patterns uncovered here. This study has only scratched the surface of the kinds of analyses that could be conducted with these data, especially as the field of computational text analysis rapidly advances.

Using open-ended responses could help researchers identify alternatives to the occupational categories provided by government institutions. Some scholars argue that occupational affiliations are becoming stronger in the new economy as workers change employers more frequently and organizational affiliations decline (Anteby et al. 2016; Barley and Kunda 2006; Carnevale, Cheah, and Rose 2011), but standard survey data may not be effective at capturing meaningful occupational communities. The findings presented here suggest cohesion varies across the occupational spectrum and over time, with different implications for worker outcomes.

In conclusion, this research brings new and unique data to bear on the meaning of occupations, as concepts and categories, and reveals how the way we measure occupation influences, and often limits, social scientists' understandings of stratification in the world of work.

\section{APPENDIX \\ $\langle$ Parts $\mathrm{A}, \mathrm{B}$, and $\mathrm{C}\rangle$}

\section{Funding}

This project received support from the National Science Foundation Graduate Research Fellowship Program (Grant No. 1839302) and the NYU Department of Sociology. Verbatim responses 1972-1998 were digitized with support from the National Science Foundation (SES1123510).

\section{Acknowledgments}

I am grateful to Bart Bonikowski, Sabrina Charles, Siwei Cheng, Sarah Cowan, Paul DiMaggio, Paula England, Kathleen Gerson, Mike Hout, Carly Knight, Andrew Levine, Virgilio Urbina Lazardi, the participants of the NYU Inequality Workshop, and four anonymous reviewers for their advice and comments on earlier versions of this article. I am also grateful to the team at the Coleridge Initiative for assistance in using the secure data platform. Remaining errors are my own. 


\section{Notes}

1. In this article, I focus on the Census Bureau's 2010 occupational scheme, which is commonly used for stratification research in the United States. The GSS has coded all of its observations, for all years, to this scheme. Future research should investigate heterogeneity within other occupational schemes, especially those used for international research, such as the International Standard Classification of Occupations (ISCO).

2. O*NET, a resource compiled by the Department of Labor based on surveys of job incumbents and occupation experts, lists common skills and tasks associated with each of the occupations in the SOC (National Center for O*NET Development 2020). However, these data are not nationally representative, and they do not include measures of heterogeneity within occupations or distributional information about skills and tasks. Similarly, the Census provides a list of job titles associated with each detailed occupation (U.S. Census Bureau 2019), but the distribution and frequency of these titles is unavailable.

3. I analyze the GSS verbatims data through a secure server that is not connected to the internet. All analyses I conduct within the secure work space have to be approved before I export them. I conduct all analyses with R (R Core Team 2019), Stata (StataCorp 2019), and Python (Van Rossum and Drake 1995). I produce figures using the R package ggplot2 (Wickham 2016). I calculate cosine and Jaccard similarity measures using the R package text2vec (Selivanov 2020). I implement Word Mover's Distance using Python's gensim library (Rehurek and Sojka 2010).

4. Beginning in 2006, the GSS began to conduct a subset of interviews in Spanish $(N=806)$. In 1982 and 1987, the GSS oversampled African Americans $(N=707)$. I also drop individuals in military occupations $(N=460)$ because the Census does not maintain lists of job titles for these occupations. Because the GSS samples at the household level, adults from larger households are somewhat underrepresented in my analysis.

5. A negligible number of individuals have nonmissing task description and missing job name $(N=31)$.

6. The system in which the verbatim responses are stored has a limit of 250 or 255 characters (about 40 words) for most years of the GSS, but there is some variation in this limit across years. Because the vast majority of responses are well below the character limit, this variation should not affect the central findings. Indeed, I ran a sensitivity test in which I truncated text responses to a maximum of 200 characters and eliminated observations from the year 2000 (the only year with a character limit below 200), and the results are robust (available upon request).

7. Stopwords are words that do not convey much information, such as "the" and "and." I use the default list of stopwords provided in the quanteda software package in $\mathrm{R}$ (Benoit et al. 2018). To correct misspellings and lemmatize, I used the hunspell (Ooms 2018) and textstem (Rinker 2018) packages. Lemmatizing refers to the process of reducing a word to its base form, (e.g., by transforming plural words into singular words). See Denny and Spirling (2018) for more information about preprocessing choices.

8. To account for word order, I create multiple formulations of each job title so (1) the final word of the title is moved to the beginning and (2) any words that appear after a comma are moved to the beginning. After matching, these formulations are combined back to the original titles. If there is more than one title with the shortest edit distance, I select the first job title alphabetically, resulting in a more conservative estimate of heterogeneity. In sensitivity tests, I selected the title from among the candidates randomly, and the results are robust (available upon request). 
9. Results of the sensitivity test using Word Mover's Distance (Table A1, Models 2 and 3) are largely consistent with the main results (Table 4). The sign on all the coefficients is the same. Gender balance remains highly statistically significant. The positive relationship between SEI and job-name similarity is more pronounced. However, the relationship between SEI and taskdescription similarity, although still negative, is no longer statistically significant, and the coefficient on proportion public sector remains negative but loses significance. These differences suggest there are more distinct but semantically similar words (as measured by pretrained word embeddings based on Google News) within high SEI and high public sector occupations. The sensitivity test results are consistent enough that I remain confident in my central findings, and I argue that cosine similarity is still the most appropriate measure for the purpose of this study. Due to the subjective nature of word meaning, there is no single, perfect approach to handling synonyms. Nevertheless, the WMD measure is intriguing and warrants further attention in future research.

\section{References}

Abbott, Andrew D. 1988. The System of Professions: An Essay on the Division of Expert Labor. Chicago, IL: University of Chicago Press.

Abowd, John M., Kevin L. McKinney, and Nellie L. Zhao. 2018. "Earnings Inequality and Mobility Trends in the United States: Nationally Representative Estimates from Longitudinally Linked Employer-Employee Data.” Journal of Labor Economics 36(S1):S183-300.

Anteby, Michel, Curtis K. Chan, and Julia DiBenigno. 2016. "Three Lenses on Occupations and Professions in Organizations: Becoming, Doing, and Relating." The Academy of Management Annals 10(1):183-244 (https://doi.org/10.1080/19416520.2016.1120962).

Autor, David H. 2014. "Skills, Education, and the Rise of Earnings Inequality among the 'Other 99 Percent." Science 344(6186):843-51.

Autor, David H. 2019. "Work of the Past, Work of the Future." NBER Working Paper 25588. Cambridge, MA: National Bureau of Economic Research.

Autor, David H., and David Dorn. 2013. "The Growth of Low-Skill Service Jobs and the Polarization of the US Labor Market." American Economic Review 103(5):1553-97.

Autor, David H., Lawrence F. Katz, and Melissa S. Kearney. 2006. "The Polarization of the U.S. Labor Market.” American Economic Review 96(2):189-94.

Avent-Holt, Dustin, Lasse Folke Henriksen, Anna Erika Hägglund, Jiwook Jung, Naomi Kodama, Silvia Maja Melzer, Eunmi Mun, Anthony Rainey, and Donald Tomaskovic-Devey. 2019. "Occupations, Workplaces or Jobs? An Exploration of Stratification Contexts Using Administrative Data." Research in Social Stratification and Mobility (https://doi.org/10.1016/j.rssm.2019.100456).

Barley, Stephen R., and Gideon Kunda. 2006. Gurus, Hired Guns, and Warm Bodies: Itinerant Experts in a Knowledge Economy. Princeton, NJ: Princeton University Press.

Baron, James N., and William T. Bielby. 1986. "The Proliferation of Job Titles in Organizations." Administrative Science Quarterly 31(4):561-86 (https://doi.org/10.2307/2392964). 
Barth, Erling, James Davis, and Richard B. Freeman. 2018. "Augmenting the Human Capital Earnings Equation with Measures of Where People Work." Journal of Labor Economics 36(S1):S71-97.

Benoit, Kenneth, Kohei Watanabe, Haiyan Wang, Paul Nulty, Adam Obeng, Stefan Müller, and Akitaka Matsuo. 2018. "quanteda: An R Package for the Quantitative Analysis of Textual Data.” Journal of Open Source Software 3(30):774 (https://doi.org/10.21105/joss.00774).

Bielby, William T., and James N. Baron. 1984. “A Woman's Place Is with Other Women: Sex Segregation within Organizations." Pp. 27-55 in Sex Segregation in the Workplace: Trends, Explanations, Remedies, edited by Barbara F. Reskin. Washington, DC: National Academy Press.

Bielby, William T., and James N. Baron. 1986. "Men and Women at Work: Sex Segregation and Statistical Discrimination." American Journal of Sociology 91(4):759-99

(https://doi.org/10.1086/228350).

Bielby, William T., and Denise D. Bielby. 1989. "Family Ties: Balancing Commitments to Work and Family in Dual Earner Households." American Sociological Review 54(5):776-89 (https://doi.org/10.2307/2117753).

Blau, Peter M., and Otis Dudley Duncan. 1967. The American Occupational Structure. New York: Wiley.

Budig, Michelle J. 2002. "Male Advantage and the Gender Composition of Jobs: Who Rides the Glass Escalator?” Social Problems 49(2):258-77 (https://doi.org/10.1525/sp.2002.49.2.258).

Campero, Santiago, and Roberto M. Fernandez. 2019. "Gender Composition of Labor Queues and Gender Disparities in Hiring." Social Forces 97(4):1487-1516

(https://doi.org/10.1093/sf/soy097).

Card, David, Ana Rute Cardoso, Joerg Heining, and Patrick Kline. 2018. "Firms and Labor Market Inequality: Evidence and Some Theory." Journal of Labor Economics 36(S1):S13-70.

Carnevale, Anthony P., Ban Cheah, and Stephen J. Rose. 2011. The College Pay Off:

Education, Occupations, Lifetime Earnings. Washington, DC: The Georgetown University Center on Education and the Workforce.

Carrington, William J., and Kenneth R. Troske. 1997. "On Measuring Segregation in Samples with Small Units." Journal of Business \& Economic Statistics 15(4):402-9.

Cech, Erin A. 2013. "Ideological Wage Inequalities? The Technical/Social Dualism and the Gender Wage Gap in Engineering." Social Forces 91(4):1147-82 (https://doi.org/10.1093/sf/sot024).

Chan, Curtis K., and Michel Anteby. 2016. "Task Segregation as a Mechanism for Within-Job Inequality: Women and Men of the Transportation Security Administration." Administrative Science Quarterly 61(2):184-216 (https://doi.org/10.1177/0001839215611447).

Charles, Maria, and Karen Bradley. 2009. "Indulging Our Gendered Selves? Sex Segregation by Field of Study in 44 Countries." American Journal of Sociology 114(4):924-76 (https://doi.org/10.1086/595942). 
Charles, Maria, and David B. Grusky. 2005. Occupational Ghettos: The Worldwide Segregation of Women and Men. Stanford, CA: Stanford University Press.

Conrad, Frederick G., Mick P. Couper, and Joseph W. Sakshaug. 2016. "Classifying OpenEnded Reports: Factors Affecting the Reliability of Occupation Codes." Journal of Official Statistics 32(1):75-92.

Corcoran, Mary E., and Paul N. Courant. 1985. "Sex Role Socialization and Labor Market Outcomes." American Economic Review 75(2):275-78.

Correll, Shelley J., Stephen Benard, and In Paik. 2007. "Getting a Job: Is There a Motherhood Penalty?” American Journal of Sociology 112(5):1297-1338 (https://doi.org/10.1086/511799).

Cotter, David A., Joan M. Hermsen, Seth Ovadia, and Reeve Vanneman. 2001. "The Glass Ceiling Effect.” Social Forces 80(2):655-81 (https://doi.org/10.1353/sof.2001.0091).

Denny, Matthew J., and Arthur Spirling. 2018. "Text Preprocessing for Unsupervised Learning: Why It Matters, When It Misleads, and What to Do about It." Political Analysis 26(2):168-89 (https://doi.org/10.1017/pan.2017.44).

Dickson, Lisa. 2010. "Race and Gender Differences in College Major Choice." The ANNALS of the American Academy of Political and Social Science 627(1):108-24

(https://doi.org/10.1177/0002716209348747).

Duncan, Otis Dudley, and Beverly Duncan. 1955. "A Methodological Analysis of Segregation Indexes." American Sociological Review 20(2):210-17.

England, Paula. 2010. "The Gender Revolution: Uneven and Stalled." Gender \& Society 24(2):149-66 (https://doi.org/10.1177/0891243210361475).

England, Paula, Andrew Levine, and Emma Mishel. 2020. "Progress toward Gender Equality in the United States Has Slowed or Stalled." Proceedings of the National Academy of Sciences 117(13):6990-97 (https://doi.org/10.1073/pnas.1918891117).

Erikson, Robert, and John H. Goldthorpe. 1992. The Constant Flux: A Study of Class Mobility in Industrial Societies. Oxford, UK: Clarendon.

Featherman, David L., and Robert M. Hauser. 1978. Opportunity and Change. New York: Academic Press.

Fernandez, Roberto M. 2001. "Skill-Biased Technological Change and Wage Inequality: Evidence from a Plant Retooling." American Journal of Sociology 107(2):273-320 (https://doi.org/10.1086/324009).

Fernandez, Roberto M., and Colette Friedrich. 2011. "Gender Sorting at the Application Interface.” Industrial Relations: A Journal of Economy and Society 50(4):591-609 (https://doi.org/10.1111/j.1468-232X.2011.00654.x).

Fernandez, Roberto M., and M. Lourdes Sosa. 2005. "Gendering the Job: Networks and Recruitment at a Call Center." American Journal of Sociology 111(3):859-904 (https://doi.org/10.1086/497257). 
Frey, Carl Benedikt, and Michael A. Osborne. 2017. "The Future of Employment: How Susceptible Are Jobs to Computerisation?" Technological Forecasting and Social Change 114:254-80 (https://doi.org/10.1016/j.techfore.2016.08.019).

Glenn, Evelyn Nakano. 2009. Unequal Freedom. Cambridge, MA: Harvard University Press.

Goldin, Claudia Dale, and Lawrence F. Katz. 2008. The Race between Education and Technology. Cambridge, MA: Harvard University Press.

Grant, Adam M., Justin M. Berg, and Daniel M. Cable. 2014. "Job Titles as Identity Badges: How Self-Reflective Titles Can Reduce Emotional Exhaustion." Academy of Management Journal 57(4):1201-25 (https://doi.org/10.5465/amj.2012.0338).

Gross, Edward. 1968. "Plus CA Change...? The Sexual Structure of Occupations over Time." Social Problems 16(2):198-208 (https://doi.org/10.2307/800005).

Hauser, Robert M., and John Robert Warren. 1997. "Socioeconomic Indexes for Occupations: A Review, Update, and Critique.” Sociological Methodology 27(1):177-298 (https://doi.org/10.1111/1467-9531.271028).

Hull, Kathleen E., and Robert L. Nelson. 2000. "Assimilation, Choice, or Constraint? Testing Theories of Gender Differences in the Careers of Lawyers." Social Forces 79(1):229-64 (https://doi.org/10.2307/2675570).

Hunt, Jennifer, and Ryan Nunn. 2019. "Is Employment Polarization Informative about Wage Inequality and Is Employment Really Polarizing?" NBER Working Paper 26064. Cambridge, MA: National Bureau of Economic Research.

Jacobs, Jerry A. 1989. Revolving Doors: Sex Segregation and Women's Careers. Stanford, CA: Stanford University Press.

Jencks, Christopher, Lauri Perman, and Lee Rainwater. 1988. "What Is a Good Job? A New Measure of Labor-Market Success.” American Journal of Sociology 93(6):1322-57.

Katz, Lawrence F., and Alan B. Krueger. 2019. "The Rise and Nature of Alternative Work Arrangements in the United States, 1995-2015." ILR Review 72(2):382-416 (https://doi.org/10.1177/0019793918820008).

Kilbourne, Barbara Stanek, Paula England, George Farkas, Kurt Beron, and Dorothea Weir. 1994. "Returns to Skill, Compensating Differentials, and Gender Bias: Effects of Occupational Characteristics on the Wages of White Women and Men." American Journal of Sociology 100(3):689-719 (https://doi.org/10.1086/230578).

Kim, ChangHwan, Jibum Kim, and Mihee Ban. 2020. "Do You Know What You Do for a Living? Occupational Coding Mismatches between Coders in the Korean General Social Survey." Research in Social Stratification and Mobility 70:100467 (https://doi.org/10.1016/j.rssm.2019.100467).

Kleiner, Morris M., and Alan B. Krueger. 2013. "Analyzing the Extent and Influence of Occupational Licensing on the Labor Market." Journal of Labor Economics 31(2):S173-202 (https://doi.org/10.1086/669060). 
Kozlowski, Austin C., Matt Taddy, and James A. Evans. 2019. "The Geometry of Culture: Analyzing the Meanings of Class through Word Embeddings." American Sociological Review 84(5):905-49 (https://doi.org/10.1177/0003122419877135).

Kusner, Matt J., Yu Sun, Nicholas I. Kolkin, and Kilian Q. Weinberger. 2015. "From Word Embeddings to Document Distances." International Conference on Machine Learning 37:95766.

Lemieux, Thomas. 2006. "Increasing Residual Wage Inequality: Composition Effects, Noisy Data, or Rising Demand for Skill?” American Economic Review 96(3):461-98.

Mandel, Hadas, and Moshe Semyonov. 2014. "Gender Pay Gap and Employment Sector: Sources of Earnings Disparities in the United States, 1970-2010." Demography 51(5):15971618 (https://doi.org/10.1007/s13524-014-0320-y).

Manning, Christopher D., Prabhakar Raghavan, and Hinrich Schütze. 2008. Introduction to Information Retrieval. Cambridge, UK: Cambridge University Press.

Mathiowetz, Nancy A. 1992. "Errors in Reports of Occupation." The Public Opinion Quarterly 56(3):352-55.

Mellow, Wesley, and Hal Sider. 1983. "Accuracy of Response in Labor Market Surveys: Evidence and Implications." Journal of Labor Economics 1(4):331-44.

Mikolov, Tomas, Kai Chen, Greg Corrado, and Jeffrey Dean. 2013. "Efficient Estimation of Word Representations in Vector Space.” ArXiv:1301.3781 [Cs.CL].

Milkman, Ruth. 2016. "Redefining 'Women's Work': The Sexual Division of Labor in the Auto Industry during World War II." Pp. 47-78 in On Gender, Labor, and Inequality. Champaign, IL: University of Illinois Press.

Mouw, Ted, and Arne L. Kalleberg. 2010. "Occupations and the Structure of Wage Inequality in the United States, 1980s to 2000s." American Sociological Review 75(3):402-31

(https://doi.org/10.1177/0003122410363564).

National Center for O*NET Development. 2020. "O*NET OnLine" (https://www.onetonline.org/).

NORC at the University of Chicago. 2016. "New Occupation and Industry Variables" (https://gss.norc.org/Documents/other/OCCIND\%20New\%20Variables\%20and\%20Instructions .pdf).

Ooms, Jereon. 2018. hunspell: High-Performance Stemmer, Tokenizer, and Spell Checker. $\mathrm{R}$ package version 3.0 (https://CRAN.R-project.org/package=hunspell).

Pele, Ofir, and Michael Werman. 2009. "Fast and Robust Earth Mover's Distances.” Pp. 460-67 in 2009 IEEE 12th International Conference on Computer Vision.

Petersen, Trond, and Laurie A. Morgan. 1995. "Separate and Unequal: OccupationEstablishment Sex Segregation and the Gender Wage Gap." American Journal of Sociology 101(2):329-65 (https://doi.org/10.1086/230727). 
Petersen, Trond, and Ishak Saporta. 2004. "The Opportunity Structure for Discrimination." American Journal of Sociology 109(4):852-901 (https://doi.org/10.1086/378536).

R Core Team. 2019. R: A Language and Environment for Statistical Computing. Vienna, Austria: R Foundation for Statistical Computing.

Rehurek, Radim, and Petr Sojka. 2010. "Software Framework for Topic Modelling with Large Corpora." Proceedings of the LREC 2010 Workshop on New Challenges for NLP Frameworks (https://doi.org/10.13140/2.1.2393.1847).

Reskin, Barbara F., and Patricia A. Roos. 2009. Job Queues, Gender Queues: Explaining Women's Inroads into Male Occupations. Philadelphia, PA: Temple University Press.

Rinker, Tyler W. 2018. textstem: Tools for Stemming and Lemmatizing Text. R package version 0.1.4 (https://cran.r-project.org/package=textstem).

Sakamoto, Arthur, and Sharron Xuanren Wang. 2020. "The Declining Significance of Occupation in Research on Intergenerational Mobility." Research in Social Stratification and Mobility 70 (https://doi.org/10.1016/j.rssm.2020.100521).

Scopp, Thomas S. 2003. "The Relationship between the 1990 Census and Census 2000 Industry and Occupation Classification Systems.” Technical Paper 65. Washington, DC: U.S. Census Bureau.

Selivanov, Dmitry. 2020. text2vec: Modern Text Mining Framework for R. R package version 0.5.1 (https://cran.r-project.org/package=text2vec).

Snyder, Benjamin H. 2016. The Disrupted Workplace: Time and the Moral Order of Flexible Capitalism. Oxford, UK: Oxford University Press.

Song, Jae, David J. Price, Fatih Guvenen, Nicholas Bloom, and Till von Wachter. 2018. "Firming up Inequality." The Quarterly Journal of Economics 134(1):1-50.

Speer, Jamin D. 2016. "How Bad Is Occupational Coding Error? A Task-Based Approach." Economics Letters 141:166-68 (https://doi.org/10.1016/j.econlet.2016.02.025).

StataCorp. 2019. Stata Statistical Software: Release 16. College Station, TX: StataCorp LLC.

Stoltz, Dustin S., and Marshall A. Taylor. 2019. "Concept Mover's Distance: Measuring Concept Engagement via Word Embeddings in Texts." Journal of Computational Social Science 2:293-313 (https://doi.org/10.1007/s42001-019-00048-6).

Strang, David, and James N. Baron. 1990. "Categorical Imperatives: The Structure of Job Titles in California State Agencies.” American Sociological Review 55(4):479-95 (https://doi.org/10.2307/2095802).

Tomaskovic-Devey, Donald. 1993a. Gender \& Racial Inequality at Work: The Sources and Consequences of Job Segregation. Ithaca, NY: Cornell University Press.

Tomaskovic-Devey, Donald. 1993b. "The Gender and Race Composition of Jobs and the Male/Female, White/Black Pay Gaps." Social Forces 72(1):45-76

(https://doi.org/10.1093/sf/72.1.45). 
Tomaskovic-Devey, Donald, Catherine Zimmer, Kevin Stainback, Corre Robinson, Tiffany Taylor, and Tricia McTague. 2006. "Documenting Desegregation: Segregation in American Workplaces by Race, Ethnicity, and Sex, 1966-2003." American Sociological Review 71(4):565-88 (https://doi.org/10.1177/000312240607100403).

Turner, Sarah E., and William G. Bowen. 1999. "Choice of Major: The Changing (Unchanging) Gender Gap.” ILR Review 52(2):289-313 (https://doi.org/10.1177/001979399905200208).

U.S. Census Bureau. 2019. "Industry and Occupation Indexes"

(https://www.census.gov/topics/employment/industry-occupation/guidance/indexes.html).

Van Rossum, Guido, and Fred L. Drake Jr. 1995. Python Reference Manual. Amsterdam: Centrum voor Wiskunde en Informatica.

Weeden, Kim A. 2002. "Why Do Some Occupations Pay More than Others? Social Closure and Earnings Inequality in the United States." American Journal of Sociology 108(1):55-101 (https://doi.org/10.1086/344121).

Weeden, Kim A., and David B. Grusky. 2005. "The Case for a New Class Map." American Journal of Sociology 111(1):141-212 (https://doi.org/10.1086/428815).

Weeden, Kim A., and David B. Grusky. 2012. "The Three Worlds of Inequality." American Journal of Sociology 117(6):1723-85 (https://doi.org/10.1086/665035).

Wickham, Hadley. 2016. ggplot2: Elegant Graphics for Data Analysis. New York: SpringerVerlag.

Wilmers, Nathan. 2020. "Job Turf or Variety: Task Structure as a Source of Organizational Inequality." Administrative Science Quarterly 65(4):1018-57

(https://doi.org/10.1177/0001839220909101).

Xie, Yu, Alexandra Killewald, and Christopher Near. 2016. "Between- and Within-Occupation Inequality: The Case of High-Status Professions." The ANNALS of the American Academy of Political and Social Science 663:53-79 (https://doi.org/10.1177/0002716215596958).

Ananda Martin-Caughey is a Sociology PhD Candidate at New York University and a National Science Foundation Graduate Research Fellow. Her research centers on work, inequality, and public policy.

Table 1. Individual-Level Descriptive Statistics for Analytic Sample

\begin{tabular}{lccc} 
& Mean & SD & $N$ \\
\hline Currently working & .63 & .48 & 58,252 \\
Men & .45 & .50 & 58,252 \\
White & .82 & .38 & 58,252 \\
Age & 46.37 & 17.21 & 58,084 \\
Unionized & .13 & .34 & 40,394 \\
Public sector & .05 & .22 & 57,962 \\
SEI (scaled) & .44 & .22 & 58,252 \\
College & .23 & .42 & 58,120 \\
Income & 45.30 & 39.16 & 36,242 \\
Job-name length & 4.03 & 4.32 & 55,343 \\
Task-description length & 12.11 & 9.18 & 53,041 \\
\hline
\end{tabular}


Note: Data come from the General Social Survey, 1972 to 2018. Currently working is a dummy variable that equals one for individuals who are working full-time or part-time at the time of the survey. Men is a dummy variable that equals one for respondents who are men. White is a dummy variable that equals one for White respondents. Age is a continuous variable. Unionized is a dummy variable that equals one for respondents who belong to a union. Public sector is a dummy variable that equals one for individuals whose current or most recent job was in a public sector industry (industry code 9370 to 9590 for GSS variable indus 10). SEI is a continuous variable that indicates the socioeconomic index of the respondent's current or most recent occupation, scaled to range from 0 to 1 . College is a dummy variable that equals one for respondents who have completed a bachelor's or graduate degree. Income is a continuous variable that measures respondents' income in thousands of 2018 dollars. Job-name length and task-description length are discrete variables that indicate the number of words respondents used when asked to describe their job name and tasks.

Table 2. Examples of Occupations with High and Low Internal Similarity

\begin{tabular}{|c|c|c|c|c|c|}
\hline By Job Name & $C$ & $N$ & By Task Description & $C$ & $N$ \\
\hline \multicolumn{6}{|l|}{ Highly similar occupations } \\
\hline Pharmacists & .75 & 58 & Postal service mail carriers & .47 & 146 \\
\hline Travel agents & .70 & 50 & $\begin{array}{l}\text { Postal service mail sorters, processors, and } \\
\text { processing machine operators }\end{array}$ & .34 & 61 \\
\hline Tellers & .64 & 205 & Dishwashers & .33 & 89 \\
\hline Bus drivers & .62 & 213 & Hairdressers, hairstylists, and cosmetologists & .32 & 441 \\
\hline Roofers & 60 & 61 & Painters, construction and maintenance & .28 & 175 \\
\hline \multicolumn{6}{|l|}{ Highly dissimilar occupations } \\
\hline $\begin{array}{l}\text { Miscellaneous entertainment } \\
\text { attendants and related workers }\end{array}$ & .03 & 61 & Business operations specialists, all other & .02 & 94 \\
\hline $\begin{array}{l}\text { Crushing, grinding, polishing, } \\
\text { mixing, and blending workers }\end{array}$ & .03 & 58 & $\begin{array}{l}\text { Office and administrative support workers, all } \\
\text { other }\end{array}$ & .02 & 231 \\
\hline $\begin{array}{l}\text { Weighers, measurers, checkers, and } \\
\text { samplers, recordkeeping }\end{array}$ & .04 & 59 & Compliance officers & .03 & 50 \\
\hline $\begin{array}{l}\text { Other installation, maintenance, and } \\
\text { repair workers }\end{array}$ & .04 & 60 & $\begin{array}{l}\text { Miscellaneous entertainment attendants and } \\
\text { related workers }\end{array}$ & .03 & 61 \\
\hline Compliance officers & .05 & 50 & Management analysts & .03 & 189 \\
\hline
\end{tabular}

Note: Data come from the General Social Survey, 1972 to 2018. $C$ indicates the average pairwise cosine similarity based on either job names or task descriptions, within occupations, ranging from 0 to 1 (least to most internally similar). $N$ indicates the number of observations. Examples are chosen from occupations with at least 50 observations. Occupations come from the 2010 Census occupational scheme.

Table 3: Occupation-Level Descriptive Statistics

\begin{tabular}{|c|c|c|c|c|c|}
\hline & \multicolumn{2}{|c|}{ Unweighted } & \multicolumn{2}{|c|}{ Weighted } & \multirow[b]{2}{*}{$N$} \\
\hline & Mean & SD & Mean & SD & \\
\hline Job-name similarity & .23 & .16 & .24 & .14 & 435 \\
\hline Task-description similarity & .10 & .07 & .10 & .06 & 430 \\
\hline SEI (scaled) & .48 & .22 & .44 & .22 & 435 \\
\hline Median income & 43.58 & 22.11 & 38.60 & 21.35 & 435 \\
\hline Proportion college & .26 & .28 & .23 & .27 & 435 \\
\hline Proportion men & .55 & .30 & .45 & .32 & 435 \\
\hline Proportion White & .83 & .10 & .82 & .10 & 435 \\
\hline Median age & 43.94 & 6.39 & 44.25 & 5.52 & 435 \\
\hline Proportion unionized & .16 & .16 & .13 & .12 & 435 \\
\hline Proportion public sector & .08 & .17 & .05 & .12 & 435 \\
\hline Size (scaled) & 1.32 & 2.34 & 5.46 & 5.76 & 435 \\
\hline
\end{tabular}

Note: Data come from the General Social Survey, 1972 to 2018. To calculate occupation-level covariates, I

collapse the GSS dataset into occupations based on the 2010 Census occupational scheme. Occupations with fewer than 10 observations are excluded. The resulting occupation sample represents 57,765 individuals (99 percent of respondents). Within this sample, $N=54,886$ for job name, and $N=52,553$ for task description. Jobname similarity and task-description similarity are continuous variables indicating the average pairwise cosine similarity based on either job names or task descriptions within the occupation. SEI is a continuous variable indicating the socioeconomic index (prestige level) of the occupation, scaled to range from 0 to 1 . Median income is a continuous variable indicating the median income of respondents within the occupation in thousands of 2018 dollars. Variables labeled proportion are continuous variables indicating the proportion of respondents 
within the occupation that meet the given criteria. Median age is a continuous variable indicating the median age of respondents within the occupation. Size is the average number of respondents, divided by 100 . To calculate descriptive statistics, I calculate the means and standard deviations across occupations unweighted and weighted by occupation size (number of observations in the GSS analytic sample). 
Table 4. Predicting Job-Name and Task-Description Similarity with Occupational Prestige

\begin{tabular}{|c|c|c|c|c|c|c|}
\hline & (1) & (2) & (3) & (4) & (5) & (6) \\
\hline & \multicolumn{3}{|c|}{ Job-Name Similarity } & \multicolumn{3}{|c|}{ Task-Description Similarity } \\
\hline \multirow[t]{2}{*}{ SEI (scaled) } & $.187 * * *$ & $.247 * * *$ & $.269 * * *$ & $-.067 * * *$ & $-.054 * * *$ & $-.048 * *$ \\
\hline & $(.039)$ & $(.040)$ & $(.042)$ & $(.014)$ & $(.016)$ & $(.018)$ \\
\hline \multirow[t]{2}{*}{ Prop. men } & & $-.071 * *$ & $-.073 *$ & & -.013 & $-.022^{*}$ \\
\hline & & $(.026)$ & $(.028)$ & & $(.010)$ & $(.011)$ \\
\hline \multirow[t]{2}{*}{ Gender balance } & & $-.774 * * *$ & $-.749 * * *$ & & $-.170 * * *$ & $-.159 * * *$ \\
\hline & & $(.097)$ & $(.101)$ & & $(.040)$ & $(.043)$ \\
\hline \multirow[t]{2}{*}{ Prop. White } & & .092 & .075 & & -.234 & -.241 \\
\hline & & $(.267)$ & $(.270)$ & & $(.173)$ & $(.177)$ \\
\hline \multirow[t]{2}{*}{ Racial balance } & & .077 & .057 & & -.413 & -.427 \\
\hline & & $(.460)$ & $(.464)$ & & $(.273)$ & $(.278)$ \\
\hline \multirow[t]{2}{*}{ Med. age } & & -.001 & -.001 & & -.000 & -.000 \\
\hline & & $(.001)$ & $(.001)$ & & $(.001)$ & $(.001)$ \\
\hline \multirow[t]{2}{*}{ Prop. union } & & & .036 & & & .041 \\
\hline & & & $(.045)$ & & & $(.034)$ \\
\hline \multirow[t]{2}{*}{ Prop. public } & & & $-.094 *$ & & & -.021 \\
\hline & & & $(.047)$ & & & $(.018)$ \\
\hline \multirow[t]{2}{*}{ Size (scaled) } & & & .001 & & & -.001 \\
\hline & & & $(.003)$ & & & $(.001)$ \\
\hline \multirow[t]{2}{*}{ Constant } & $.138 * * *$ & .243 & .246 & $.134 * * *$ & $.421^{*}$ & $.429 *$ \\
\hline & $(.018)$ & $(.294)$ & $(.296)$ & $(.008)$ & $(.187)$ & $(.190)$ \\
\hline Observations & 435 & 435 & 435 & 430 & 430 & 430 \\
\hline Adjusted $R^{2}$ & .064 & .195 & .200 & .048 & .084 & .089 \\
\hline
\end{tabular}

Note: Data come from the General Social Survey, 1972 to 2018. The unit of analysis is detailed occupations. In Models 1, 2, and 3, the dependent variable is the average pairwise cosine

similarity based on job names. In Models 4,5 , and 6 , the dependent variable is the average pairwise cosine similarity based on task descriptions. Gender balance equals (prop. men) $\times$ (prop. women). Racial balance equals (prop. White) $\times$ (prop. non-White). Size refers to the number of observations in the GSS analytic sample for each occupation, divided by 100 . All regressions use ordinary least squares and robust standard errors. Standard errors are in parentheses.

$* p<.05 ; * * p<.01 ; * * * p<.001$ (two-tailed tests) 
Table 5. Predicting Job-Name and Task-Description Similarity with Occupational Income and Occupational Education

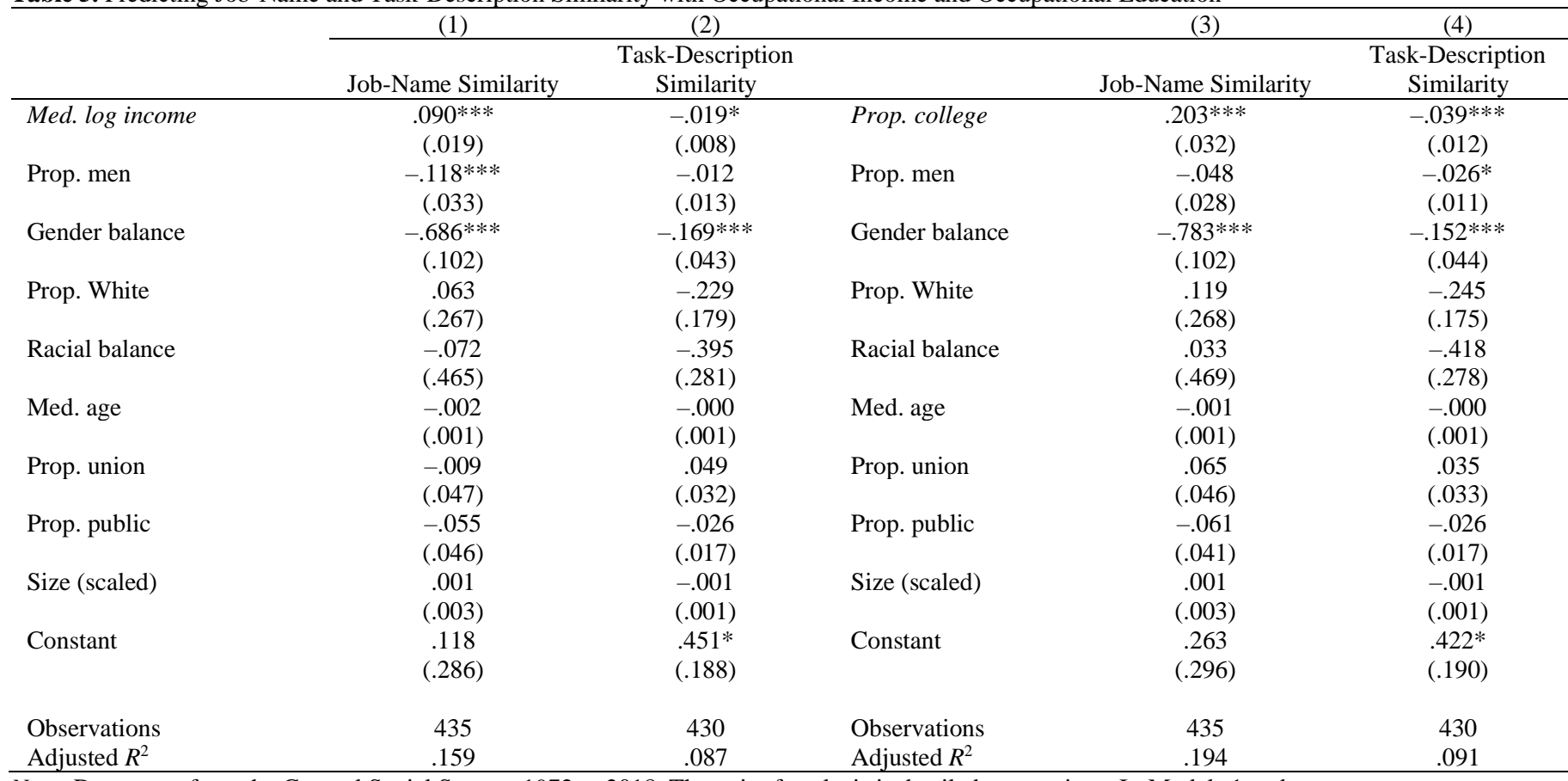

Note: Data come from the General Social Survey, 1972 to 2018. The unit of analysis is detailed occupations. In Models 1 and 3 , the dependent variable is the average pairwise cosine similarity based on job names. In Models 2 and 4, the dependent variable is the average pairwise cosine similarity based on task descriptions. Gender balance equals (prop. men) $\times$ (prop. women). Racial balance equals (prop. White) $\times$ (prop. non-White). Size refers to the number of observations in the GSS analytic sample for each occupation, divided by 100 . All regressions use ordinary least squares and robust standard errors. Standard errors are in parentheses.

$* p<.05 ; * * p<.01 ; * * * p<.001$ (two-tailed tests).

Table 6. Predicting Decade-Specific Job-Name and Task-Description Similarity

\begin{tabular}{lcc}
\hline & $(1)$ & $(2)$ \\
\cline { 2 - 3 } SEI (scaled) & Job-Name Similarity & Task-Description Similarity \\
Prop. men & $.238^{* * *}$ & $-.037^{* * *}$ \\
& $(.024)$ & $(.011)$ \\
Gender balance & $.043^{* *}$ & -.012 \\
& $(.015)$ & $(.007)$ \\
Prop. White & $.435^{* * *}$ & $-.148^{* * *}$ \\
& $(.051)$ & $(.024)$ \\
Racial balance & $.151^{* *}$ & .008 \\
& $(.047)$ & $(.027)$ \\
Med. age & $.192^{*}$ & .026 \\
& $(.092)$ & $(.050)$ \\
Prop. union & -.001 & .000 \\
& $(.001)$ & $(.000)$ \\
Prop. public & $.059^{*}$ & .019 \\
& $(.026)$ & $(.012)$ \\
Size (scaled) & $.109^{* * *}$ & $-.030 * *$ \\
& $(.025)$ & $(.010)$ \\
Constant & $.018^{* *}$ & -.001 \\
& $(.006)$ & $.003)$ \\
& .104 & $.158^{* * *}$
\end{tabular}


Decade factor included?

Yes

2101

Observations

Adjusted $R^{2}$

Note: Data come from the General Social Survey, 1972

1 , the dependent variable is the average pairwise cosine similarity based on job names. the average pairwise cosine similarity based on task descriptions. Gender balance equals (prop. men) $\times$ (prop. women). Racial balance equals (prop. White) $\times$ (prop. non-White). Size refers to the number of observations in the GSS analytic sample for each occupation, divided by 100 . All regressions use ordinary least squares and robust standard errors. Standard errors are in parentheses.

$* p<.05 ; * * p<.01 ; * * * p<.001$ (two-tailed tests).
Yes

2088

.051 
$\underline{\text { Table 7. Gender Segregation Based on Occupations and Job Titles by Major Occupational Groups }}$

\begin{tabular}{|c|c|c|c|c|c|c|}
\hline \multirow[b]{2}{*}{ Major Occupational Groups } & \multirow[b]{2}{*}{ No. of Workers } & \multirow[b]{2}{*}{ Prop. Men } & \multirow[b]{2}{*}{$\begin{array}{l}\text { No. Detailed } \\
\text { Occupations }\end{array}$} & \multirow[b]{2}{*}{ No. of Job Titles } & \multicolumn{2}{|c|}{ Segregation Across } \\
\hline & & & & & $\begin{array}{c}\text { Detailed } \\
\text { Occupations }\end{array}$ & Job Titles \\
\hline $\begin{array}{l}\text { Management, professional, and related } \\
\text { occupations }\end{array}$ & 17,277 & .46 & 189 & 2,993 & $.46^{\dagger \dagger}$ & $.59^{\dagger \dagger}$ \\
\hline Service occupations & 9,314 & .3 & 68 & 1,073 & $.57^{\dagger \dagger}$ & $.69^{\dagger \dagger}$ \\
\hline Sales and office occupations & 14,499 & .27 & 70 & 1,732 & $.48^{\dagger \dagger}$ & $.61^{\dagger \dagger}$ \\
\hline $\begin{array}{l}\text { Natural resources, construction, and } \\
\text { maintenance occupations }\end{array}$ & 5,324 & .93 & 81 & 1,508 & $.49^{\dagger \dagger}$ & $.76^{\dagger}$ \\
\hline $\begin{array}{l}\text { Production, transportation, and material moving } \\
\text { occupations }\end{array}$ & 8,929 & .61 & 117 & 3,084 & $.51^{\dagger \dagger}$ & $.74^{\dagger \dagger}$ \\
\hline Total & 55,343 & .45 & 525 & 10,390 & $.56^{\dagger \dagger}$ & $.68^{\dagger \dagger}$ \\
\hline
\end{tabular}

Note: Data come from the General Social Survey, 1972 to 2018. Segregation is measured using the Duncan Segregation Index, ranging from 0 to 1 (least to most segregated). Significance daggers are based on permutation tests. I simulate segregation under the null hypothesis that there is no unmeasured segregation at the higher level of aggregation by randomly allocating individuals to job titles within detailed occupations (or detailed occupations within major occupations). $\dagger \dagger$

Indicates the point estimate for segregation falls above the simulated segregation in at least 99 percent of trials. $\dagger$ Indicates 95 percent. See Appendix C for additional details. 

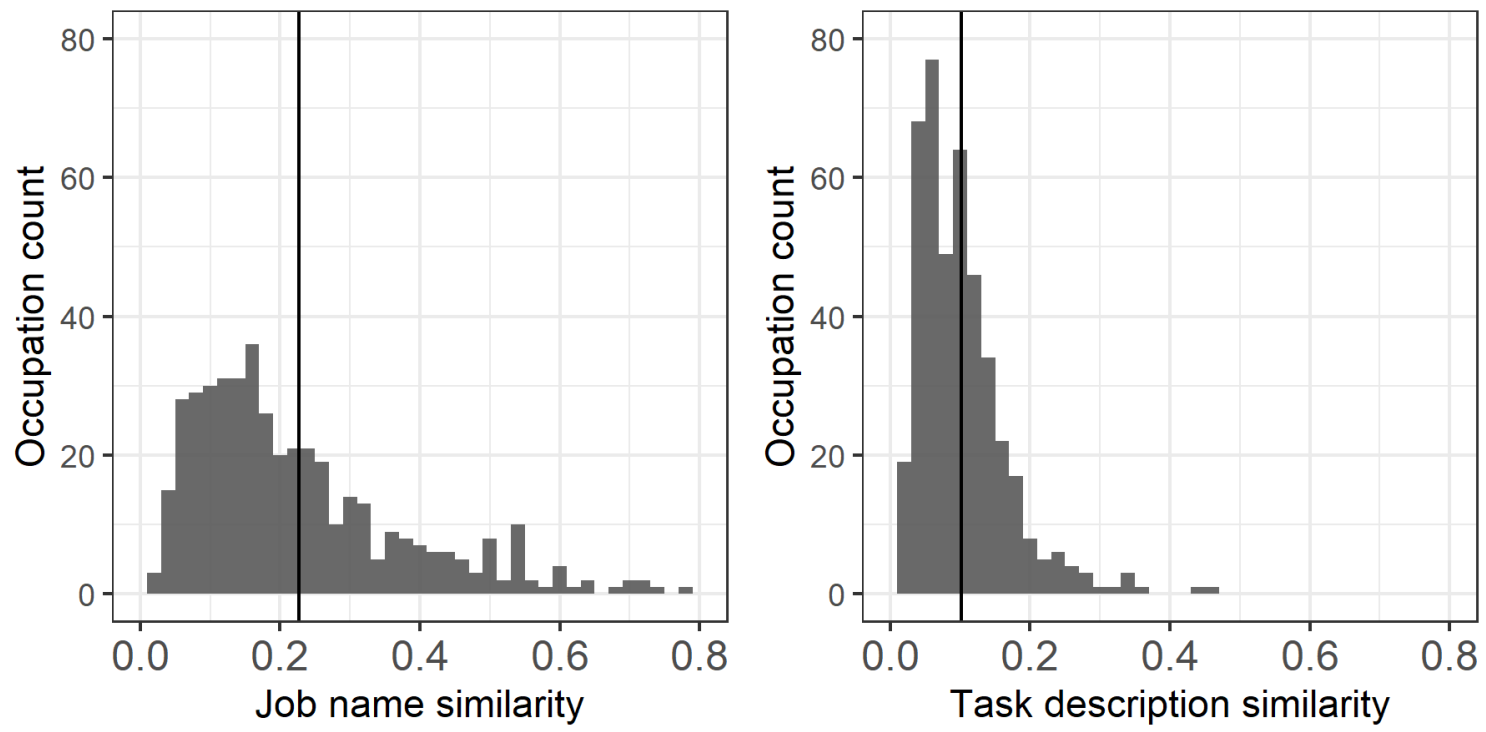

Figure 1. Distribution of Within-Occupation Similarity, by Job Names and Task Descriptions Note: Data come from the General Social Survey, 1972 to 2018. $N=435$ occupations with at least 10 observations for job name, and $N=430$ occupations with at least 10 observations for task description. Similarity is measured based on the average cosine similarity between job names or task descriptions within occupations and can range from 0 to 1 , from least to most internally similar. Vertical lines indicate mean similarity. 


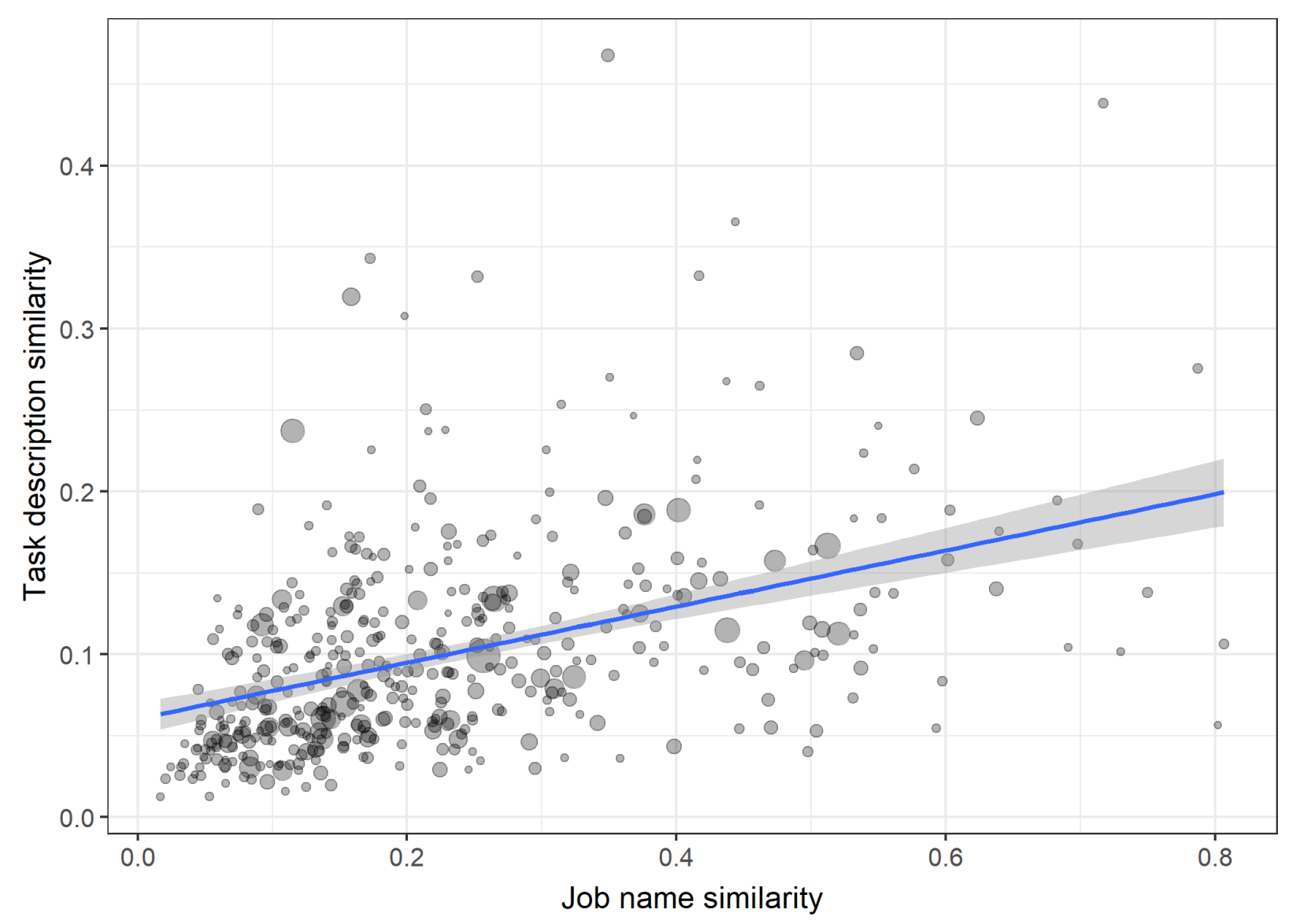

Figure 2. Occupational Similarity by Job Names and Task Descriptions

Note: Data come from the General Social Survey, 1972 to 2018. $N=430$ occupations with at least 10 observations for job name and task description. Similarity is measured based on the average cosine similarity between job names or task descriptions within occupations. The measure ranges from 0 to 1 , from least to most internal similarity. Dot sizes correspond to the number of observations per occupation. The solid line and the shaded area represent the linear fit, weighted by occupation size, and the 95 percent confidence interval. 


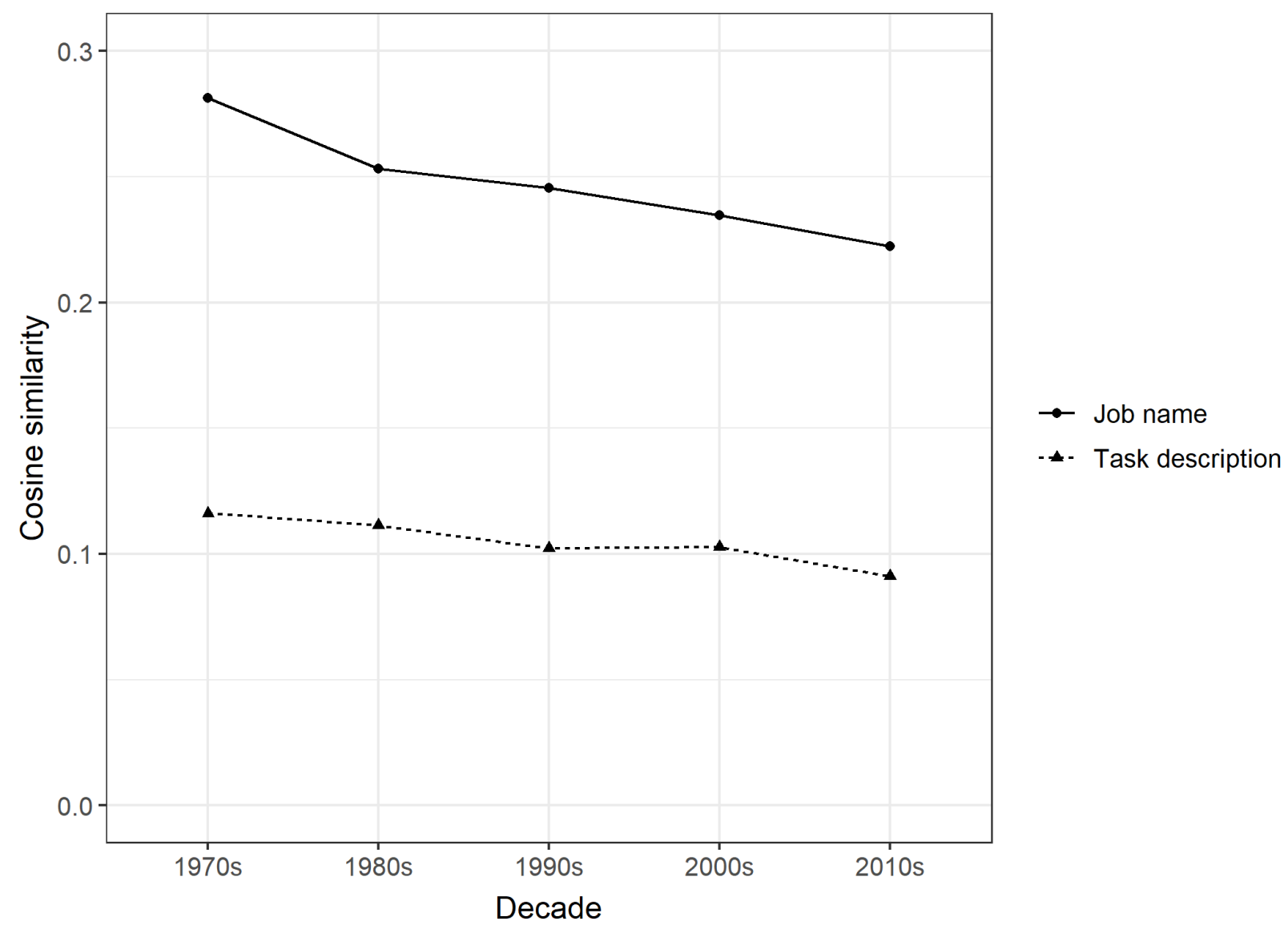

Figure 3. Occupational Similarity (Weighted Mean) by Job Name and Task Description, 1972 to 2018

Note: Data come from the General Social Survey, 1972 to 2018. Each point represents the mean similarity across occupations, weighted by occupation size. Similarity is measured based on the average cosine similarity between job names or task descriptions within occupations within decades. The measure ranges from 0 to 1 , from least to most internal similarity. Occupations with fewer than two observations in a given decade are excluded. $N=2,119$ occupation-decades for job name. $N=2,105$ occupation-decades for task description. 


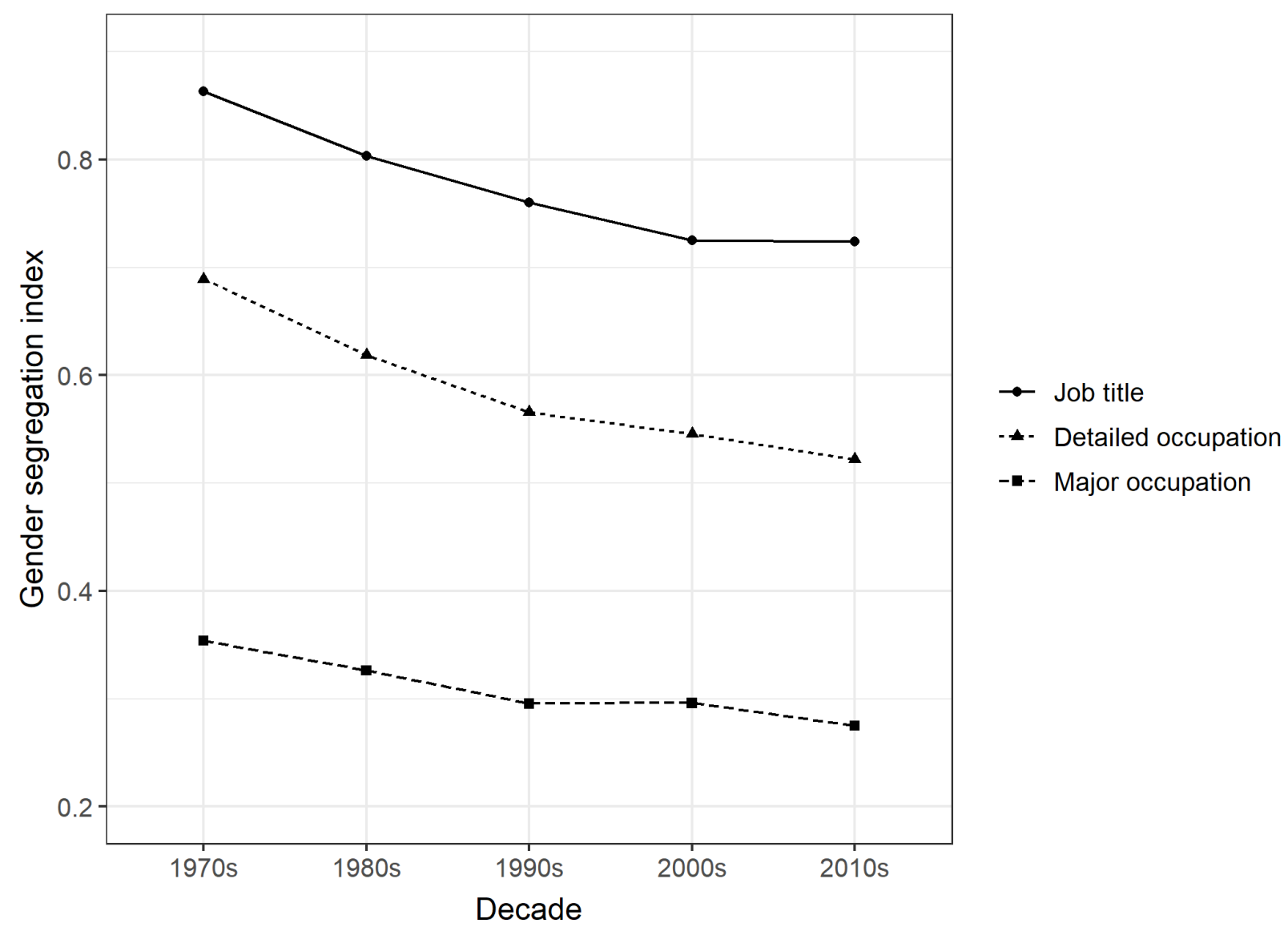

Figure 4. Gender Segregation at Three Levels, 1972 to 2018

Note: Data come from the General Social Survey, 1972 to 2018. Segregation is measured using the Duncan Segregation Index, ranging from 0 to 1 (least to most segregated). The index indicates the proportion of men (or women) who would have to switch categories (job titles, detailed occupations, or major occupations) for the distribution across categories to be equal. $N=55,343$ individuals. The data contain 5 major occupations, 525 detailed occupations, and 10,390 job titles. 


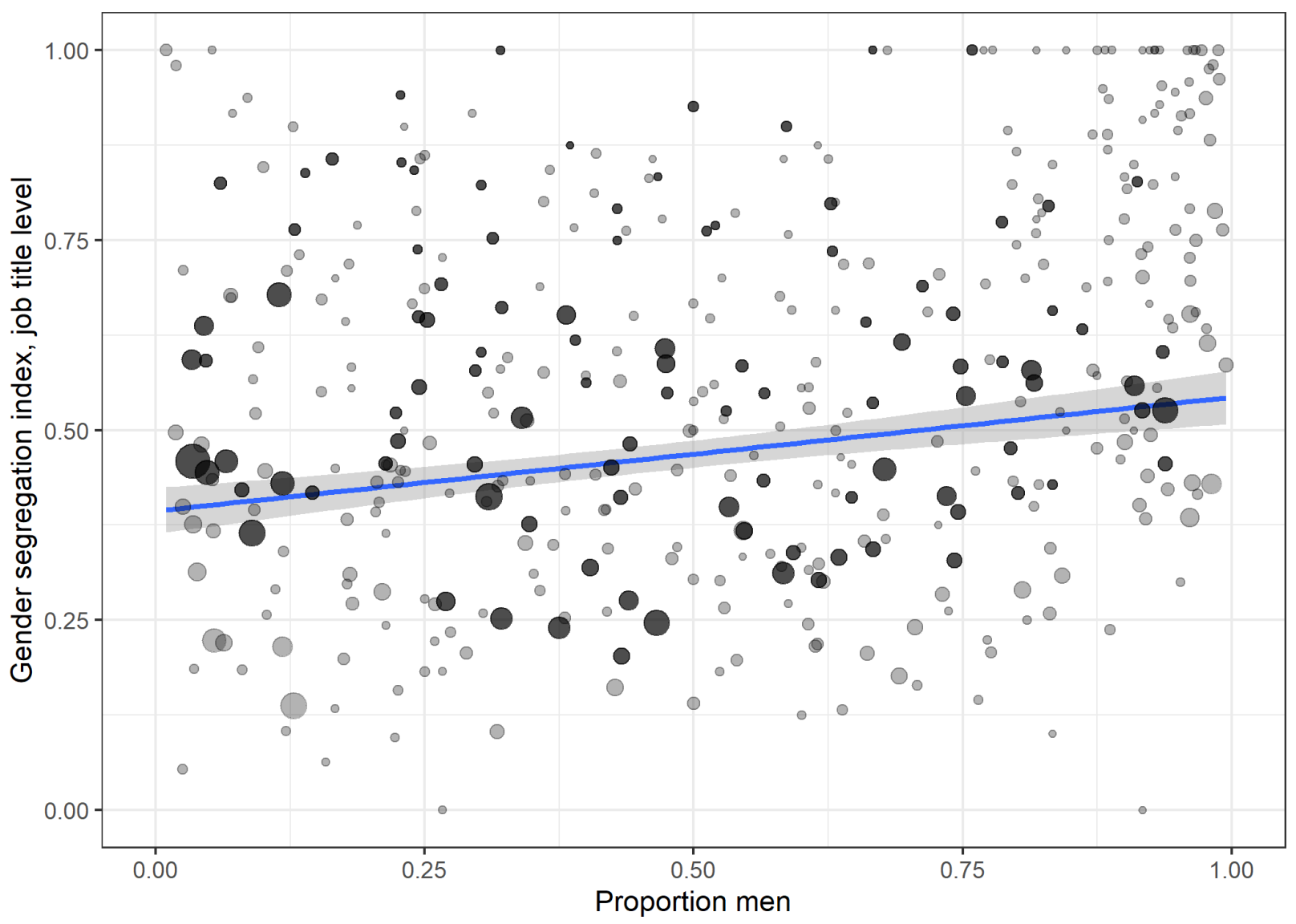

Figure 5. Job Title-Level Gender Segregation by Proportion Men Note: Data come from the General Social Survey, 1972 to 2018. $N=409$ occupations with at least 10 observations and a combination of men and women. Dot sizes correspond to the number of observations per occupation. Darker shaded dots $(N=103)$ indicate the gender segregation index at the job-title level is significant at $p<.05$ based on permutation tests. See Appendix $\mathrm{C}$ for details. The solid line and the shaded area represent the linear fit, weighted by occupation size, and the 95 percent confidence interval. 


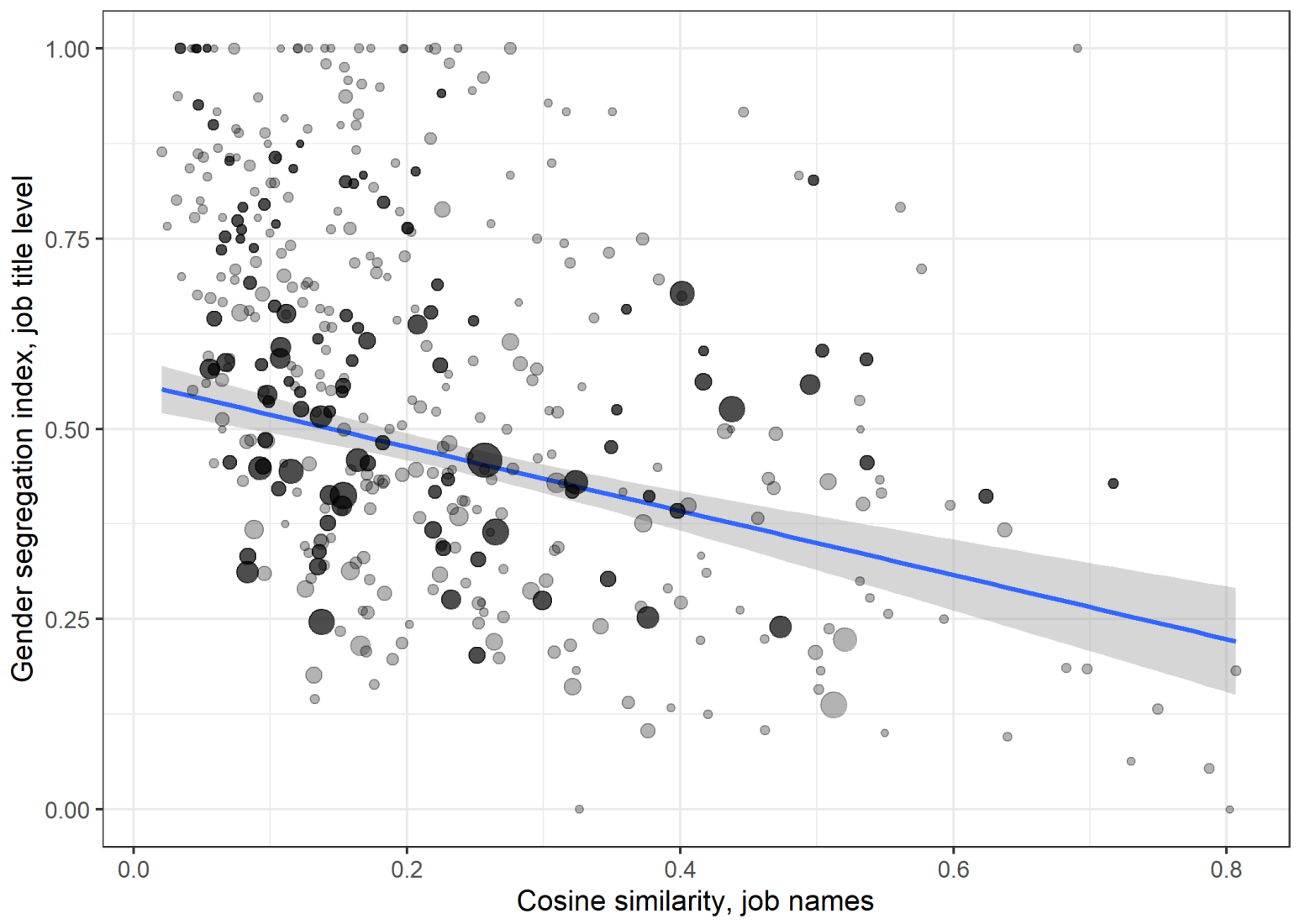

Figure 6. Job Title-Level Gender Segregation by Occupational Similarity

Note: Data come from the General Social Survey, 1972 to 2018. $N=409$ occupations with at least 10 observations and a combination of men and women. Dot sizes correspond to the number of observations per occupation. Darker shaded dots $(N=103)$ indicate the gender segregation index at the job-title level is significant at $p<.05$ based on permutation tests. See Appendix C for details. The solid line and the shaded area represent the linear fit, weighted by occupation size, and the 95 percent confidence interval.

\section{APPENDIX}

Part A. Sensitivity Tests

Table A1. Predicting Jaccard Similarity and Word Mover's Distance

\begin{tabular}{lcccc} 
& $(1)$ & $(2)$ & $(3)$ & $(4)$ \\
\cline { 2 - 5 } & $\begin{array}{c}\text { Job-Name Similarity } \\
(\text { Jaccard) }\end{array}$ & $\begin{array}{c}\text { Task-Description } \\
\text { Similarity (Jaccard) }\end{array}$ & $\begin{array}{c}\text { Job-Name Similarity (Word } \\
\text { Mover's Distance } \times-1)\end{array}$ & $\begin{array}{c}\text { Task-Description Similarity } \\
\text { (Word Mover's Distance } \times-1)\end{array}$ \\
\hline SEI (scaled) & $.215^{* * *}$ & $-.029^{* *}$ & $.341^{* * *}$ & -.032 \\
Prop. men & $(.037)$ & $(.011)$ & $(.048)$ & $(.018)$ \\
& $-.064^{* *}$ & -.011 & $-.095^{* *}$ & -.015 \\
Gender balance & $(.025)$ & $(.006)$ & $(.033)$ & $(.011)$ \\
& $-.614^{* * *}$ & $-.076^{* *}$ & $-.857 * * *$ & $-.163 * * *$ \\
Prop. White & $(.086)$ & $(.025)$ & $(.115)$ & $(.039)$ \\
& .092 & -.108 & .021 & -.180
\end{tabular}




\begin{tabular}{|c|c|c|c|c|}
\hline & $(.219)$ & $(.096)$ & $(.295)$ & $(.144)$ \\
\hline \multirow[t]{2}{*}{ Racial balance } & .078 & -.195 & -.072 & -.328 \\
\hline & $(.384)$ & $(.151)$ & $(.509)$ & $(.232)$ \\
\hline \multirow[t]{2}{*}{ Med. age } & -.001 & -.000 & -.002 & -.000 \\
\hline & $(.001)$ & $(.000)$ & $(.001)$ & $(.001)$ \\
\hline \multirow{2}{*}{ Prop. union } & .027 & .023 & .040 & .033 \\
\hline & $(.038)$ & $(.021)$ & $(.050)$ & (.029) \\
\hline \multirow[t]{2}{*}{ Prop. public } & $-.075^{*}$ & -.017 & -.075 & -.025 \\
\hline & $(.038)$ & $(.010)$ & $(.051)$ & $(.016)$ \\
\hline \multirow[t]{2}{*}{ Size (scaled) } & .001 & -.001 & .001 & -.001 \\
\hline & $(.002)$ & $(.001)$ & $(.003)$ & $(.001)$ \\
\hline \multirow[t]{2}{*}{ Constant } & .168 & .201 & $-.908 * *$ & $-.940 * * *$ \\
\hline & $(.243)$ & $(.105)$ & $(.331)$ & $(.158)$ \\
\hline Observations & 435 & 430 & 435 & 430 \\
\hline Adjusted $R^{2}$ & .186 & .077 & .224 & .077 \\
\hline
\end{tabular}

Note: Data come from the General Social Survey, 1972 to 2018. The unit of analysis is detailed occupations. The dependent variables are the average pairwise Jaccard similarity, in terms of job names (Model 1) and task descriptions (Model 2), and Word Mover's Distance $\times-1$ in terms of job names (Model 3) and task descriptions (Model 4). All regressions use ordinary least squares and robust standard errors. Standard errors are in parentheses.

$* p<.05 ; * * p<.01 ; * * * p<.001$ (two-tailed tests).

Table A2. Predicting Similarity with Sample Restrictions (Currently Working and Excluding Self-Employed)

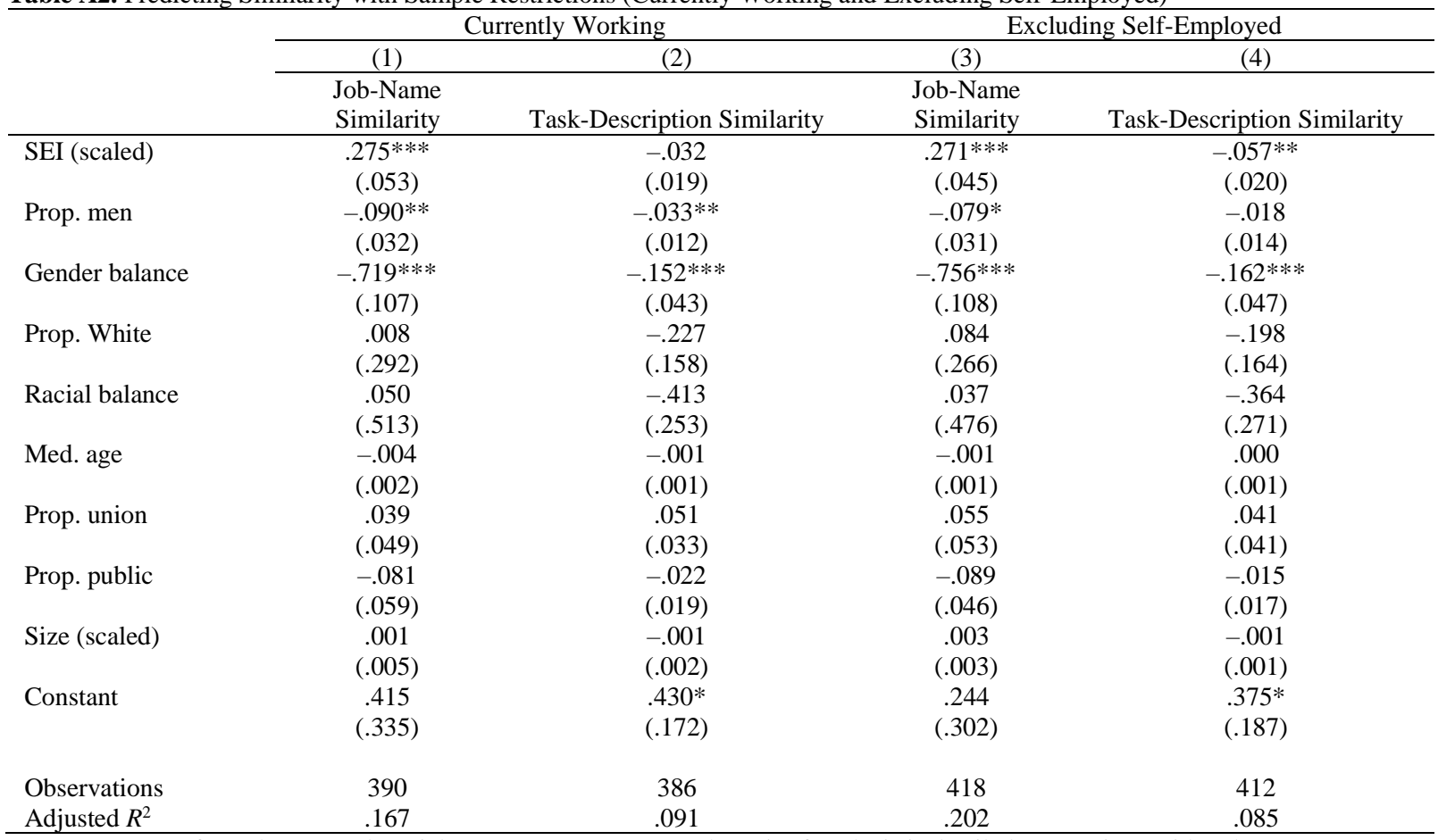

Note: Data come from the General Social Survey, 1972 to 2018. The unit of analysis is detailed occupations with at least 10 observations. The dependent variables are the average pairwise cosine similarity for job names or task descriptions. In Models 1 and 2, the sample is restricted to individuals who were currently working full-time or part-time at the time of the survey. In Models 3 and 4, the sample excludes individuals who are not self-employed. All regressions use ordinary least squares and robust standard errors. Standard errors are in parentheses.

$* p<.05 ; * * p<.01 ; * * * p<.001$ (two-tailed tests). 
Table A3. Predicting Similarity with Very Small Occupations Included

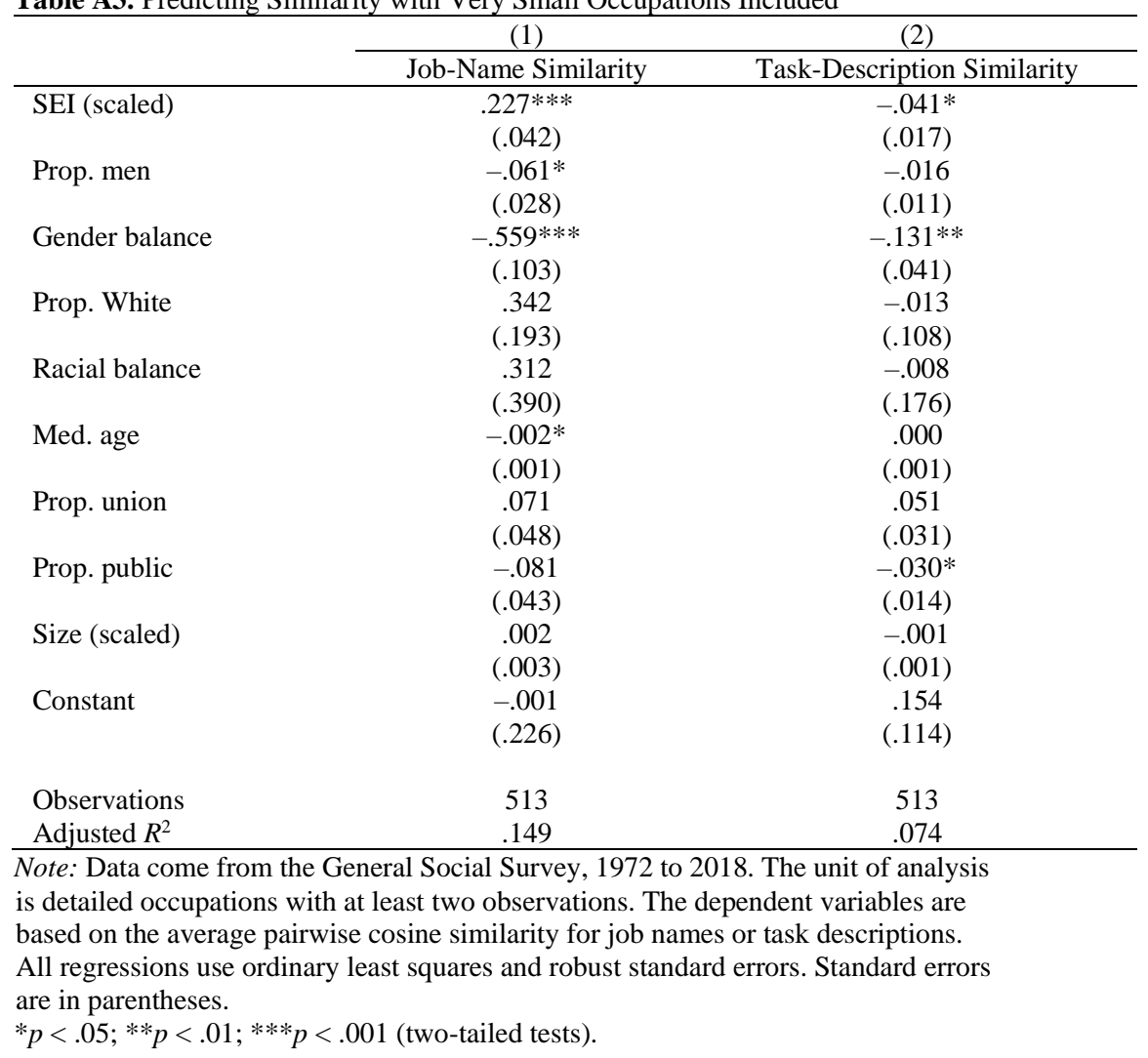

Table A4. Predicting Similarity with Alternative Text Preprocessing

\begin{tabular}{lcc}
\hline & $(1)$ & $(2)$ \\
\cline { 2 - 3 } SEI (scaled) & Job-Name Similarity & Task-Description Similarity \\
Prop. men & $.190^{* * *}$ & -.020 \\
& $(.032)$ & $(.011)$ \\
Gender balance & $.066^{* *}$ & $-.018^{*}$ \\
& $(.023)$ & $(.007)$ \\
Prop. White & $-.552^{* * *}$ & $-.065^{*}$ \\
& $(.080)$ & $(.026)$ \\
Racial balance & .045 & -.085 \\
& $(.225)$ & $(.106)$ \\
Med. age & -.001 & -.154 \\
& $(.384)$ & $(.169)$ \\
Prop. union & -.001 & .000 \\
& $(.001)$ & $(.000)$ \\
Prop. public & .045 & .024 \\
Size (scaled) & $(.038)$ & $(.020)$ \\
Constant & -.043 & -.007 \\
& $(.037)$ & $(.011)$ \\
& .001 & $-.002^{* * *}$ \\
& $(.002)$ & $(.001)$ \\
& .207 & .207 \\
& $(.247)$ & $(.114)$
\end{tabular}




$\begin{array}{lll}\text { Observations } & 435 & 430 \\ \text { Adjusted } R^{2} & .169 & .051\end{array}$

Note: Data come from the General Social Survey, 1972 to 2018 . The unit of analysis is detailed occupations with at least 10 observations. The dependent variables are based on the average pairwise cosine similarity for job names or task descriptions, without lemmatizing, correcting spelling errors, or removing stopwords. All regressions use ordinary least squares and robust standard errors. Standard errors are in parentheses. $* p<.05 ; * * p<.01 ; * * * p .001$ (two-tailed tests).

Table A5. Predicting Similarity with Alternative Specifications to Address Missing Data Concerns

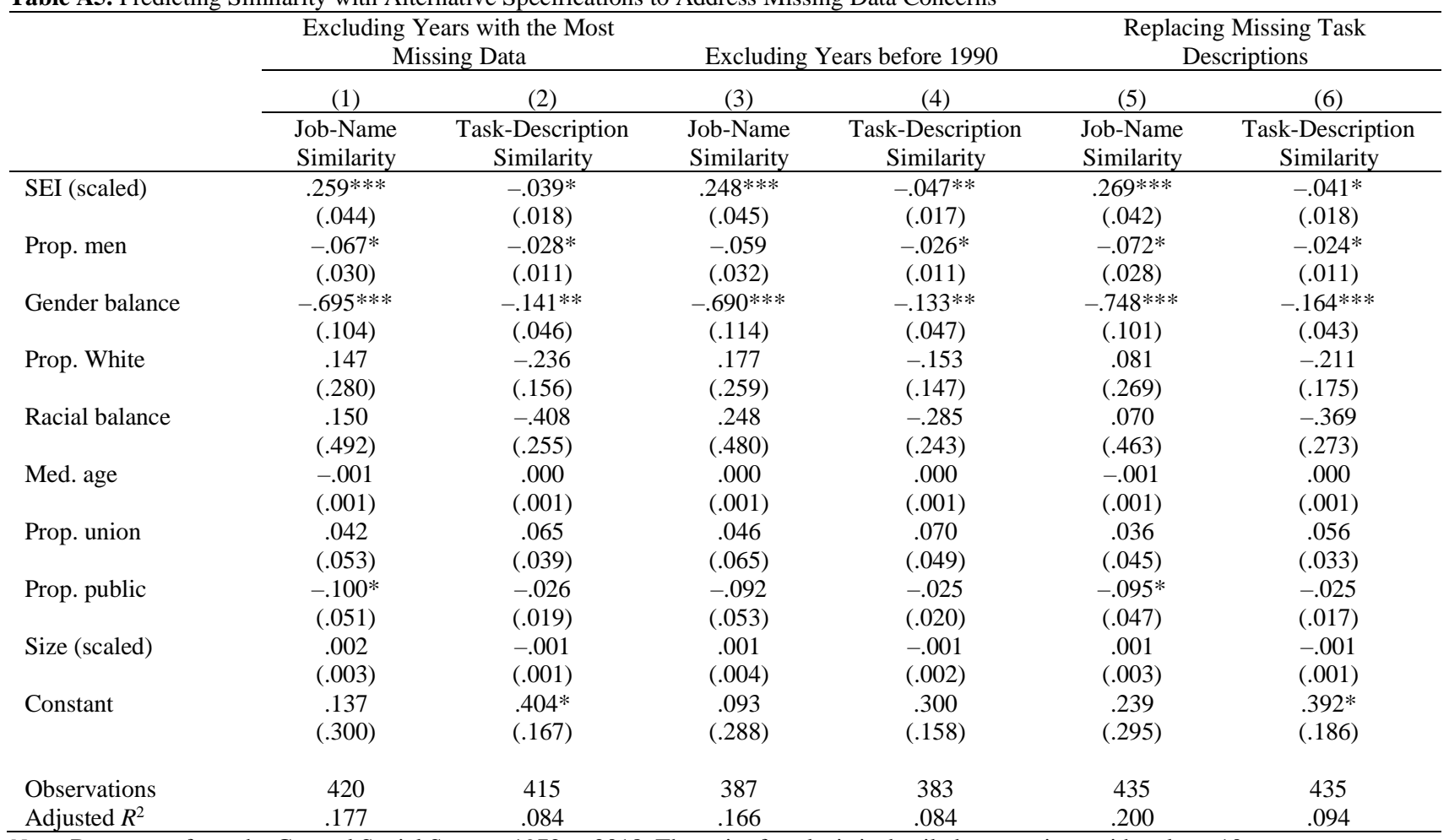

Note: Data come from the General Social Survey, 1972 to 2018. The unit of analysis is detailed occupations with at least 10 observations. The dependent variables are the average pairwise cosine similarity for job names or task descriptions. In Models 1 and 2, the sample excludes years with 10 percent or more missing data for job name (1972-1977, 1985, and 1987). In Models 3 and 4, the sample excludes years before 1990. In Models 5 and 6, missing task descriptions are replaced with nonmissing job names. All regressions use ordinary least squares and robust standard errors. Standard errors are in parentheses.

$* p<.05 ; * * p<.01 ; * * *<.001$ (two-tailed tests).

Table A6. Predicting Similarity, Excluding NEC Occupations and Adjusting for Occupation Name Length

\begin{tabular}{lcccc} 
& \multicolumn{2}{c}{ Excluding NEC Occupations } & \multicolumn{2}{c}{ Adjusting for Name Length } \\
\cline { 2 - 5 } & $(1)$ & $-.047^{*}$ & $(3)$ & $(4)$ \\
\hline SEI (scaled) & $.284^{* * *}$ & $(.019)$ & $.207^{* * *}$ & $-.065^{* *}$ \\
Prop. men & $(.044)$ & $-.026^{*}$ & $-.042)$ & $(.020)$ \\
& $-.096^{* *}$ & $(.012)$ & $(.027)$ & -.015 \\
Gender balance & $(.029)$ & $-.147^{* *}$ & $-.697^{* * *}$ & $(.011)$ \\
& $-.783^{* * *}$ & $(.046)$ & $(.096)$ & $-.146^{* * *}$ \\
Prop. White & $(.107)$ & -.217 & .244 & $(.043)$ \\
& .219 & $(.202)$ & $(.255)$ & $(.195$
\end{tabular}




\begin{tabular}{|c|c|c|c|c|}
\hline Racial balance & $\begin{array}{c}.327 \\
(.505)\end{array}$ & $\begin{array}{l}-.365 \\
(.314)\end{array}$ & $\begin{array}{c}.346 \\
(.440)\end{array}$ & $\begin{array}{l}-.350 \\
(.291)\end{array}$ \\
\hline \multirow[t]{2}{*}{ Med. age } & -.002 & -.000 & -.001 & -.000 \\
\hline & $(.001)$ & $(.001)$ & $(.001)$ & $(.001)$ \\
\hline \multirow[t]{2}{*}{ Prop. union } & .035 & .042 & .047 & .044 \\
\hline & $(.047)$ & $(.035)$ & $(.044)$ & $(.034)$ \\
\hline \multirow[t]{2}{*}{ Prop. public } & -.081 & -.020 & -.072 & -.015 \\
\hline & $(.047)$ & $(.018)$ & $(.046)$ & $(.018)$ \\
\hline \multirow[t]{2}{*}{ Size (scaled) } & -.001 & -.002 & .000 & -.002 \\
\hline & $(.003)$ & $(.001)$ & $(.002)$ & $(.001)$ \\
\hline \multirow[t]{2}{*}{ Name length } & & & $-.003 * * *$ & $-.001 * * *$ \\
\hline & & & $(.000)$ & $(.000)$ \\
\hline \multirow[t]{2}{*}{ Constant } & .126 & .403 & .152 & $.405^{*}$ \\
\hline & $(.322)$ & $(.216)$ & $(.276)$ & $(.196)$ \\
\hline Observations & 387 & 383 & 435 & 430 \\
\hline Adjusted $R^{2}$ & .210 & .079 & .284 & .126 \\
\hline \multicolumn{5}{|c|}{$\begin{array}{l}\text { Note: Data come from the General Social Survey, } 1972 \text { to } 2018 \text {. The unit of analysis is detailed occupations with at least } 10 \\
\text { observations. The dependent variables are the average pairwise cosine similarity for job names or task descriptions. In Models } \\
1 \text { and } 2 \text {, the sample excludes NEC ("not elsewhere classified") occupations, that is, occupations that include the words "other" } \\
\text { or "miscellaneous" in the occupation name. In Models } 3 \text { and } 4 \text {, the sample includes NEC occupations but adjusts for } \\
\text { occupation name length (number of characters). All regressions use ordinary least squares and robust standard errors. Standard } \\
\text { errors are in parentheses. } \\
* p<.05 ; * * p<01 ; * * p<.001 \text { (two-tailed tests). }\end{array}$} \\
\hline
\end{tabular}

Table A7. Predicting Similarity, Weighted by Occupation Size

\begin{tabular}{lcc}
\hline & $(1)$ & $(2)$ \\
\cline { 2 - 3 } & Job-Name Similarity & Task-Description Similarity \\
\hline SEI (scaled) & $.244^{* * *}$ & -.018 \\
Prop. men & $.060)$ & $(.020)$ \\
& -.048 & $-.042^{* *}$ \\
Gender balance & $.039)$ & $(.013)$ \\
& $-.712^{* * *}$ & $-.144 * *$ \\
Prop. White & $(.129)$ & $(.047)$ \\
& .258 & $-.703^{* * *}$ \\
Racial balance & $(.472)$ & $(.177)$ \\
& .451 & $-1.144 * * *$ \\
Med. age & $(.863)$ & $(.309)$ \\
& -.002 & -.000 \\
Prop. union & $(.002)$ & $(.001)$ \\
& $.218^{*}$ & $.131^{* *}$ \\
Prop. public & $(.093)$ & $(.043)$ \\
& $-.183^{* *}$ & $-.060^{*}$ \\
Constant & $(.059)$ & $(.024)$ \\
& .070 & $.892^{* * *}$ \\
Observations & $(.550)$ & $(.200)$ \\
Adjusted $R^{2}$ & & 430 \\
\hline
\end{tabular}

Note: Data come from the General Social Survey, 1972 to 2018. The unit of analysis is detailed occupations with at least 10 observations. The dependent variables are based on the average pairwise cosine similarity for job names or task descriptions. Regressions are weighted by occupation size (i.e., number of observations per occupation in the GSS). All regressions use ordinary least squares and robust standard errors. Standard errors are in parentheses. $* p<.05 ; * * p<.01 ; * * *<.001$ (two-tailed tests).

Part B. Response Length by Gender and Education 
The following regression results show how the length (number of tokens) of responses to questions about spouses' and parents' occupations (job names and task descriptions) varies by respondents' gender and education.

Table B1. Length of Description of Family Members' Occupation, by Gender of Respondent

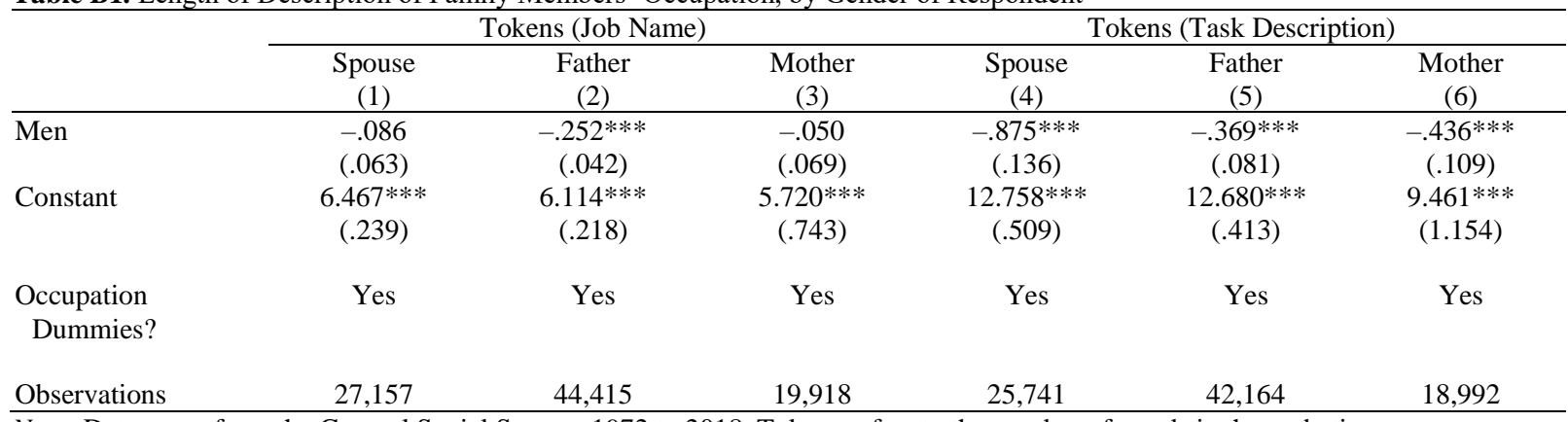

Note: Data come from the General Social Survey, 1972 to 2018 . Tokens refers to the number of words in the verbatim

responses about the respondent's spouses' and parents' job names and tasks. Men refers to the gender of the respondent.

Occupation dummies refer to the occupation being described (of the spouse or parent). Standard errors are in parentheses.

$* p<.05 ; * *<.01 ; * * * p<.001$ (two-tailed tests).

Table B2. Length of Description of Family Members' Occupation, by Education of Respondent

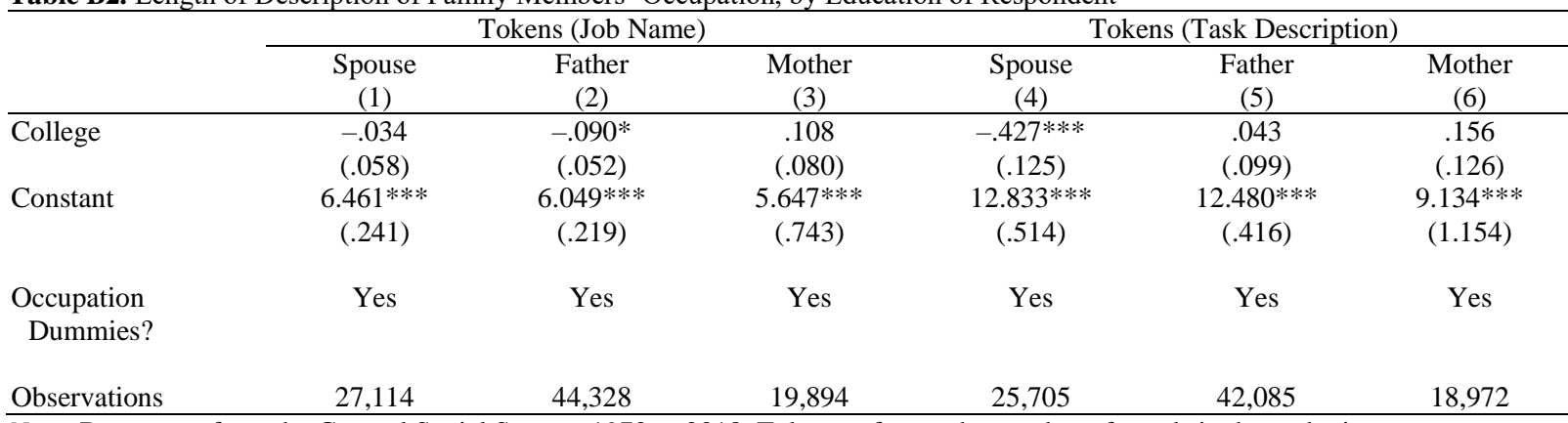

Note: Data come from the General Social Survey, 1972 to 2018 . Tokens refers to the number of words in the verbatim responses about the respondent's spouses' and parents' job names and tasks. College refers to whether or not the respondent completed a bachelor's or graduate degree. Occupation dummies refer to the occupation being described (of the spouse or parent). Standard errors are in parentheses.

$* p<.05 ; * *<.01 ; * * *<<.001$ (two-tailed tests).

\section{Part C. Segregation Index Permutation Tests}

One of the concerns when measuring Duncan's Segregation Index $(D)$ is the possibility that small unit size can artificially inflate measured segregation. As units decrease in size (e.g., from major occupations to detailed occupations or from detailed occupations to job titles), the portion of $D$ that may be attributed to random allocation increases (Carrington and Troske 1997). The fact that I have many job titles with just one or two observations may artificially inflate the measured segregation. For example, say we have a job title that has only five observations in the data, and all five of those observations are women. The fact that these five individuals are women could be due to the fact that the job title is heavily dominated by women, or it could be due to random allocation. To address this concern, I conduct a series of tests to simulate $D$ under the null hypothesis that there is no unmeasured segregation in higher levels of aggregation and then compare the distribution of simulated $D$ to the point estimate. The steps are as follows: 
1. Calculate $D$ at the level of major occupations. This estimate is called $D M$.

2. Randomly assign the individuals in the dataset to detailed occupations within major occupations. For example, within the major occupation "management, professional, and related occupations," there are approximately 8,000 men and 9,000 women in the dataset, and there are 189 detailed occupations. Keeping the distribution of detailed occupations fixed, I randomly allocate the 8,000 men and 9,000 women to the detailed occupations within the major occupation. I then follow the same process for the other major occupations.

3. Once individuals are randomly matched to detailed occupations, calculate the $D$ index at the level of detailed occupations. I call this estimate $B D D$ (baseline $D$ for detailed occupations).

4. Repeat steps 2 and 31,000 times to generate a distribution of $B D D$.

5. Calculate the point estimate for $D$ at the level of detailed occupations based on the real data $(D D)$.

6. Compare $D D$ with the distribution of $B D D$. If $D D$ falls above the 99th percentile of $B D D$, this generates a significance level of $p<.01(* *)$, meaning we can be relatively confident the increase in segregation at the detailed occupation level compared with the major occupation level is not simply due to small unit size.

7. Repeat the same procedure to compare $D T$ (segregation measured at the job-title level) to the distribution of $B D T$.

Table C1. Segregation Index by Decade with Permutation Test Results

\begin{tabular}{lcc|c|ccc|ccc}
\hline Decade & $N$ & Prop. Men & DM & DD & BD99 & DD - BD99 & DT & BT99 & DT - BT99 \\
\hline $1970 \mathrm{~s}$ & 6,848 & .484 & $\mathbf{. 3 5 4}$ & $\mathbf{. 6 8 9}$ & .407 & .283 & $\mathbf{. 8 6 3}$ & .834 & .030 \\
$1980 \mathrm{~s}$ & 11,605 & .448 & $\mathbf{. 3 2 6}$ & $\mathbf{. 6 1 9}$ & .368 & .250 & $\mathbf{. 8 0 3}$ & .781 & .022 \\
$1990 \mathrm{~s}$ & 12,354 & .445 & $\mathbf{. 2 9 5}$ & $\mathbf{. 5 6 6}$ & .349 & .216 & $\mathbf{. 7 6 0}$ & .734 & .026 \\
$2000 \mathrm{~s}$ & 13,826 & .453 & $\mathbf{. 2 9 6}$ & $\mathbf{. 5 4 6}$ & .349 & .197 & $\mathbf{. 7 2 5}$ & .704 & .021 \\
$2010 \mathrm{~s}$ & 10,710 & .448 & $\mathbf{. 2 7 5}$ & $\mathbf{. 5 2 2}$ & .328 & .194 & $\mathbf{. 7 2 4}$ & .712 & .012 \\
& & & & & & & & & \\
Total & 55,343 & .453 & $\mathbf{. 2 9 5}$ & $\mathbf{. 5 5 9}$ & .317 & .242 & $\mathbf{. 6 8 4}$ & .650 & .034 \\
\hline
\end{tabular}

Note: Segregation indices are in bold. DM refers to the segregation index at the major occupation level. DD refers to the segregation index at the detailed occupation level. DT refers to the segregation index at the job-title level. BD99 refers to the 99th percentile of the simulated segregation index at the detailed occupation level under random allocation. BT99 refers to the 99th percentile of the simulated segregation index at the job-title level under random allocation. 